\title{
Subseasonal Variability of Rossby Wave Breaking and Impacts on Tropical Cyclones during the North Atlantic Warm Season
}

\author{
WEIWEI LI, ${ }^{\text {a }}$ ZHUO WANG, AND GAN ZHANG ${ }^{\text {b }}$ \\ Department of Atmospheric Sciences, University of Illinois at Urbana-Champaign, Urbana, Illinois \\ Melinda S. Peng \\ CSRA/Naval Research Laboratory, Monterey, California \\ STANLEy G. BENJAMIN \\ NOAA/Earth System Research Laboratory, Boulder, Colorado \\ MING ZHAO \\ NOAA/Geophysical Fluid Dynamics Laboratory, Princeton, New Jersey
}

(Manuscript received 20 December 2017, in final form 13 September 2018)

\begin{abstract}
This study investigates the subseasonal variability of anticyclonic Rossby wave breaking (AWB) and its impacts on atmospheric circulations and tropical cyclones (TCs) over the North Atlantic in the warm season from 1985 to 2013. Significant anomalies in sea level pressure, tropospheric wind, and humidity fields are found over the tropical-subtropical Atlantic within 8 days of an AWB activity peak. Such anomalies may lead to suppressed TC activity on the subseasonal time scale, but a significant negative correlation between the subseasonal variability of AWB and Atlantic basinwide TC activity does not exist every year, likely due to the modulation of TCs by other factors. It is also found that AWB occurrence may be modulated by the MaddenJulian oscillation (MJO). In particular, AWB occurrence over the tropical-subtropical west Atlantic is reduced in phases 2 and 3 and enhanced in phases 6 and 7 based on the Real-Time Multivariate MJO (RMM) index. The impacts of AWB on the predictive skill of Atlantic TCs are examined using the Global Ensemble Forecasting System (GEFS) reforecasts with a forecast lead time up to 2 weeks. The hit rate of tropical cyclogenesis during active AWB episodes is lower than the long-term-mean hit rate, and the GEFS is less skillful in capturing the variations of weekly TC activity during the years of enhanced AWB activity. The lower predictability of TCs is consistent with the lower predictability of environmental variables (such as vertical wind shear, moisture, and low-level vorticity) under the extratropical influence.
\end{abstract}

\section{Introduction}

Rossby waves may break when propagating into a region where the zonal mean flow is weak and waves become highly nonlinear (McIntyre and Palmer 1983). Thorncroft et al. (1993) illustrated two types of Rossby wave breaking (RWB) based on the upper-level trough

\footnotetext{
${ }^{\text {a }}$ Current affiliation: NCAR/Research Applications Laboratory, and Developmental Testbed Center, Boulder, Colorado.

${ }^{\mathrm{b}}$ Current affiliation: Atmospheric and Oceanic Sciences Program, Princeton University, New Jersey.
}

Corresponding author: Weiwei Li, weiweili@ucar.edu behavior: anticyclonic RWB (AWB) and cyclonic RWB (CWB). Anticyclonic RWB is characterized by positively tilted troughs being advected anticyclonically and occurs preferentially on the equatorward side of the jet, while cyclonic RWB features negatively tilted troughs wrapping up cyclonically and occurs mostly on the poleward side of the jet. Breaking Rossby waves induce mixing of the surrounding air and are usually manifested as the irreversible overturning of the potential vorticity (PV) contours on isentropic surfaces (McIntyre and Palmer 1983, 1985).

Rossby wave breaking is closely related to midlatitude weather and low-frequency climate variability on the subseasonal and longer time scales (e.g., Rivière and 
Orlanski 2007; Martius et al. 2007; Strong and Magnusdottir 2008). For example, RWB is connected to the development of some midlatitude wintertime weather regimes such as blocking over the North Atlantic (e.g., Michel and Rivière 2011). Through the interaction with the midlatitude jet via eddy feedback, RWB is dynamically linked to the North Atlantic Oscillation (NAO), the Pacific-North America (PNA) pattern, and the west Pacific pattern (e.g., Benedict et al. 2004; Woollings et al. 2008; Martius et al. 2007; Rivière and Orlanski 2007; Rivière 2010; Franzke et al. 2011). In addition, RWB affects water vapor transport into the Arctic (Liu and Barnes 2015) and is closely related to atmospheric rivers that have substantial impacts on the regional hydrology (e.g., Payne and Magnusdottir 2014; Hu et al. 2017).

Rossby wave breaking can also facilitate tropicalextratropical interaction. Frequent AWB equatorward of the midlatitude jet injects dry and cold extratropical air of high PV into the lower latitudes, thereby modulating the subtropical and tropical atmospheric conditions (e.g., Postel and Hitchman 1999; Waugh and Funatsu 2003; de Vries et al. 2016). In boreal winter, significant regional anomalies of wave breaking activity appear during certain phases of the Madden-Julian oscillation (MJO; Madden and Julian 1972) (Moore et al. 2010), and RWB plays an important role in connecting the variability of extratropical circulations (such as the NAO) with the MJO (e.g., Cassou 2008). MacRitchie and Roundy (2016) suggested a two-way interactive relationship between the AWB and the MJO in boreal winter. They found that the active MJO convection over the eastern Indian Ocean and the Maritime Continent is associated with enhanced AWB over the central North Pacific. Meanwhile, the residual cutoff lows from AWB may enhance the MJO during its eastward propagation.

Previous research mainly focused on RWB in the cold season, partly because the weather/climate phenomena (such as midlatitude cyclones, the NAO, and the MJO) are stronger in winter than in summer. However, RWB remains active in the warm season (Postel and Hitchman 1999; Abatzoglou and Magnusdottir 2006; MacRitchie and Roundy 2016) and may impact the summertime weather and climate (Zhang et al. 2016, 2017). Strong and Magnusdottir (2009) showed that AWB over the North Pacific occurs more frequently in summer than in winter, and that the impacts of the AWB on the Pacific decadal oscillation (PDO) in summer are comparable to those in winter despite weaker summertime surface heat fluxes. Samanta et al. (2016) found that the summertime AWB can lead to dry episodes of the Indian summer monsoon by bringing high-PV air equatorward. Another interesting issue is the link between the warm-season AWB and tropical cyclone (TC) activity. Anticyclonic
RWB has been found to occasionally trigger TC formation via the tropical transition mechanism (Davis and Bosart 2004; Galarneau et al. 2015; Bentley et al. 2017). A significant negative correlation, however, exists between AWB and Atlantic TC activity on the seasonal time scale (Zhang et al. 2016, 2017), as active AWB can induce frequent equatorward intrusion of dry, cold extratropical air, thereby enhancing the vertical wind shear and mid- to upper-tropospheric dryness and suppressing seasonal TC activity.

Given the strong impacts of RWB on Atlantic TCs on the seasonal time scale, it is natural to ask whether RWB affects the variability and predictability of Atlantic TCs on the subseasonal time scale. Previous studies on the subseasonal variability of TCs mostly focused on the MJO (e.g., Vitart et al. 2012, 2017). The MJO is an important source of predictability on the subseasonal time scale and influences TC activity by altering the environmental conditions (such as vertical wind shear, midlevel moisture, and low-level vorticity) and synoptic wave activity (e.g., Maloney and Hartmann 2000; Klotzbach and Oliver 2015). The MJO indices are commonly used as predictors in statistical models for subseasonal prediction (e.g., Leroy and Wheeler 2008; Slade and Maloney 2013), and skillful forecast of the MJO in a dynamic model is generally regarded as the basis for skillful subseasonal prediction (e.g., Belanger et al. 2010; Vitart et al. 2010; Elsberry et al. 2014; Li et al. 2016). In contrast to the extensive work on the MJO, the impacts of RWB on the subseasonal variability and predictability of TCs have not been well investigated. In addition, it is unclear whether the link between RWB and the MJO in summer is similar to that in winter (MacRitchie and Roundy 2016).

This study seeks to address the following scientific questions: 1) How is AWB associated with large-scale atmospheric anomalies? 2) How does AWB affect TC activity and predictability on the subseasonal time scale? 3) How is the MJO related to AWB activity in boreal summer? We will focus on the North Atlantic basin and the warm season from July to October (JASO), a time period when the Atlantic TCs and RWB are both active. Since RWB equatorward of the midlatitude jet is predominantly anticyclonic during JASO (Zhang et al. 2016), we will focus on AWB. No consensus exists on the specific definition of the subseasonal time scale (National Academies of Sciences, Engineering, and Medicine 2016). In this paper, "subseasonal" refers to the time range from 7 days to 12 weeks, which is beyond the range of deterministic numerical weather prediction and includes the time scale of medium-range forecasts (up to 15 days; Vitart et al. 2012, 2017). The datasets and methods used for the investigation are described in section 2 . The subseasonal 
variability of $\mathrm{AWB}$, the associated atmospheric anomalies, and the connection to the $\mathrm{MJO}$ are presented in section 3 . Section 4 discusses the impacts of AWB on TC activity and TC predictability, followed by a summary and discussion in section 5 .

\section{Data and methods}

\section{a. Data and $A W B$ detection}

We used the 6-hourly European Centre for MediumRange Weather Forecasts (ECMWF) interim reanalysis (ERA-Interim, hereinafter ERA-I; Dee et al. 2011) from 1985 to 2013 (29 years) to detect AWB events and to investigate the atmospheric anomalies associated with AWB. The $1.0^{\circ} \times 1.0^{\circ}$ daily Global Precipitation Climatology Project (GPCP; Huffman et al. 2001) precipitation data during 1997-2013 were used to examine the precipitation anomalies associated with AWB. The ERA-I data with the original resolution of approximately $0.7^{\circ}$ were coarsened to $1.0^{\circ} \times 1.0^{\circ}$ resolution to analyze atmospheric anomalies and to $2.5^{\circ} \times 2.5^{\circ}$ resolution for computational efficiency in AWB detection.

AWB events were identified based on PV overturning on the $350-\mathrm{K}$ isentropic surface (or the reversal of the meridional PV gradient) (e.g., Abatzoglou and Magnusdottir 2006; Strong and Magnusdottir 2008). Theoretically, a wave breaking region encloses the poleward-intruding low-PV tongue, the equatorward-intruding high-PV tongue, the wave breaking axis, and the tropopause fold point (see Fig. 1 in Postel and Hitchman 1999). A wave breaking event is often characterized by strong asymmetry (Peters and Waugh 1996; Gabriel and Peters 2008) with predominance of a one-sided poleward or equatorward breaking branch (see Fig. 1 in Gabriel and Peters 2008). To highlight the equatorward impacts of AWB, we defined the location and the area of an AWB event based on the centroid and the extent of the equatorward intrusion of the high-PV tongue, respectively. Strictly speaking, the AWB location and area defined this way represent only the high-PV tongues in association with AWB. For the sake of brevity, we refer them to as the "AWB location" and "AWB area," respectively, in the rest of the text.

Anomalies of atmospheric variables and various indices were calculated by removing the seasonal cycle and the seasonal (JASO) mean. The seasonal cycle was defined as the daily mean on each calendar day averaged over 1985-2013, and the removal of the seasonal mean was to exclude the interannual variability.

\section{b. GEFS reforecasts, TC detection, and indices}

The predictability of TCs and environmental variables were evaluated using the Global Ensemble Forecasting
System (GEFS) Reforecast version 2 (Hamill et al. 2013). The dataset includes one control and 10 perturbed ensemble members. The reforecasts were initialized once daily (at 0000 UTC) from the Climate Forecast System Reanalysis (CFSR; Saha et al. 2014) through February 2011 and from the operational Gridpoint Statistical Interpolation (GSI) analysis afterward (Kleist et al. 2009; Hamill et al. 2013). The reforecasts used a fixed model version (v9.0.1) and was run at the resolution of T254L42 ( $\sim 55 \mathrm{~km}$ at the equator) for the first week and at the resolution of T190L $42(\sim 70 \mathrm{~km}$ at the equator) from day +8 to day +16 . Global models at these resolutions are sufficient to represent TC formations and have been used to provide guidance on TC formation forecasting in the past (e.g., Halperin et al. 2013). An earlier study also showed that the GEFS can skillfully capture the seasonality and interannual variability of TC formations and has promising skill in predicting the active and inactive periods of TC activity over the Atlantic (Li et al. 2016). Both the reanalysis and reforecast data were analyzed for the time period of JASO from 1985 to 2013.

Tropical cyclones in the GEFS reforecasts were detected using the Geophysical Fluid Dynamics Laboratory (GFDL) vortex tracker (Marchok 2002). A TC was identified as a warm-core vortex lasting longer than $72 \mathrm{~h}$ continuously with $10-\mathrm{m}$ above sea level maximum wind speed higher than 32 knots $\left(\mathrm{kt} ; 1 \mathrm{kt} \approx 0.51 \mathrm{~m} \mathrm{~s}^{-1}\right)(\mathrm{Li}$ et al. 2016). The threshold of the wind speed was adjusted according to the data resolution (Walsh et al. 2007). Vortices forming poleward of $40^{\circ} \mathrm{N}$ were regarded as extratropical cyclones and were excluded from the analysis. We classified the model-generated TCs into four categories based on the International Best Track Archive for Climate Stewardship (IBTrACS v03r05; Knapp et al. 2010), including hits, early geneses, late geneses, and false alarms. A hit, an early genesis, and a late genesis were defined as a model TC forming within a $5^{\circ}$ radius of an observed TC. A hit was required to take place within $\pm 24 \mathrm{~h}$ of the observed genesis time, and an early genesis or a late genesis was defined if a model TC occurred beyond $\pm 24 \mathrm{~h}$ but within $\pm 120 \mathrm{~h}$ of the observed genesis time (Wang et al. 2018). The remaining model-generated TCs were categorized as false alarms.

Several TC indices were defined to quantify TC activity. "TC days" is the sum of the lifetime of all active TCs with a unit of days; "accumulated cyclone energy" (ACE) is the integration of the squares of the 6-hourly maximum sustained surface wind speed $\left(\mathrm{kt}^{2}\right.$; Bell et al. 2000) over the lifetime of all active TCs in a basin; and "weekly cyclone energy" (WCE) and "weekly TC days" (WTD) are the total cyclone energy and TC days, 
respectively, over a 1-week time period centered on the day of interest ( $\mathrm{Li}$ et al. 2016).

The daily Real-Time Multivariate MJO (RMM) index (Wheeler and Hendon 2004) was used to investigate the relationship between AWB and the MJO on the global scale. In addition, a local MJO index was defined based on the space-time filtered $200-\mathrm{hPa}$ velocity potential (VP200) over the tropical Atlantic. The VP200 is chosen over the 850 - or 200 -hPa zonal wind, or outgoing longwave radiation because the wind field of the MJO is not strongly coupled to convection over the Western Hemisphere, and VP200 exhibits a robust relation with convective/divergence and TC activity over the western North Atlantic (Ventrice et al. 2013). A space-time filter was first applied to the meridional mean $\left(10^{\circ} \mathrm{S}-10^{\circ} \mathrm{N}\right)$ VP200 to extract the variations with zonal wavenumbers 0-10 and periods of 30-91 days ( $\mathrm{Li}$ et al. 2014), and then the local MJO index was defined as the areal average of the filtered VP200 over $100^{\circ}-30^{\circ} \mathrm{W}$.

\section{c. Metrics of predictive skill}

The predictive skill of tropical cyclogenesis was evaluated by the hit rate $H$. To include early geneses and late geneses, we modified the conventional definition of the hit rate as

$$
H=(a+e+f) /(a+e+f+c),
$$

where $a$ is a hit, $c$ is a miss, $e$ is an early genesis, and $f$ is a late genesis. The hit rate was first calculated for individual ensemble members, and then the ensemble mean was taken. The predictive skill of an environmental variable related to TCs, such as vertical wind shear, precipitable water, and low-level relative vorticity, was measured by the ensemble spread of the variable, which was defined as the root-mean-squared difference between ensemble members and the ensemble mean (Whitaker and Loughe 1998). TC predictive skill is used as a proxy for the practical predictability (Wang et al. 2018).

The ERA-I dataset was used to identify active AWB episodes when examining the predictive skill associated with AWB. Since the GEFS reforecasts are initialized by the CFSR during most of the studied period, it would be ideal to identify active AWB episodes using the CFSR. Our visual inspection of individual AWB events (not shown) suggests a good agreement between the CFSR and the ERA-I in capturing AWB events, but quantitative differences in AWB area exist. Because of a spurious long-term trend of AWB activity in the CFSR (Papin 2017), we chose to use the ERA-I to determine active AWB episodes, although the impacts of AWB on the predictive skill of the GEFS may be underestimated due to the inconsistency between the two datasets.
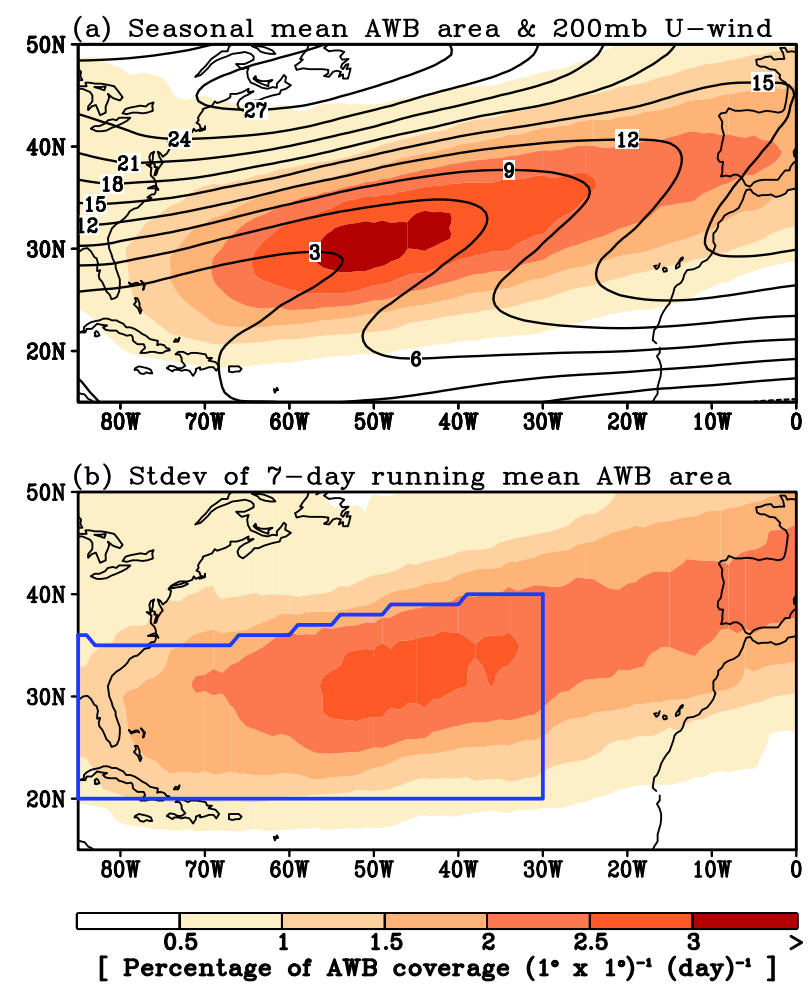

FIG. 1. (a) Climatological seasonal-mean density function of AWB area [percentage of AWB coverage $\left(1^{\circ} \times 1^{\circ}\right)^{-1} \mathrm{day}^{-1}$; shaded] and the mean 200-hPa zonal wind ( $\mathrm{m} \mathrm{s}^{-1}$; contours), and (b) the standard deviation of the 7-day running-mean AWB density function during JASO 1985-2013. The blue polygon highlights the domain $\left(85^{\circ}-30^{\circ} \mathrm{W}\right.$ and from $20^{\circ} \mathrm{N}$ to $10^{\circ}$ south of the $200-\mathrm{hPa}$ jet axis) where an AWB index is defined.

\section{Subseasonal variability of AWB}

\section{a. Climatology of $A W B$ activity and $A W B$ index}

We first examined the spatial distribution of AWB activity by calculating the density function of AWB area, which was defined as the total AWB area within a $10^{\circ} \times 10^{\circ}$ box centered on each $1.0^{\circ}$ grid. Figure 1 a shows the warm-season climatology of AWB activity over the North Atlantic overlaid with the $200-\mathrm{hPa}$ zonal wind. The maxima of AWB activity occur on the anticyclonicshear (equatorward) side of the jet (Thorncroft et al. 1993; Martius et al. 2007; MacRitchie and Roundy 2016). Consistent with some previous studies (e.g., Abatzoglou and Magnusdottir 2006), strong AWB activity has a southwest-to-northeast elongated pattern across the North Atlantic, which is aligned with the climatological tropical upper-tropospheric trough (TUTT). Since our definition of AWB location focuses on the high-PV tongue of an AWB event, the AWB maxima are equatorward of those identified in the studies based on the AWB axis or the tropopause fold point (e.g., Postel and Hitchman 1999). Figure 1b shows the standard deviation 
of the 7-day running-mean density of AWB area during JASO 1985-2013 after removing the seasonal cycle and seasonal mean. The pattern is similar to the seasonalmean distribution, and the strong subseasonal variability of AWB is nearly collocated with the strong seasonalmean AWB.

A domain over the western North Atlantic, including the largest subseasonal variability $\left(85^{\circ}-30^{\circ} \mathrm{W}\right.$ and from $20^{\circ} \mathrm{N}$ to $10^{\circ}$ south of the 200 -hPa jet axis; see Fig. 1b), was selected to define an AWB index. The domain is set over the western to central North Atlantic because AWB in this region has a stronger influence on the basinwide TC activity than that over the eastern North Atlantic (Zhang et al. 2017). Although the domain selection is somewhat subjective, the analyses in the following sections are not qualitatively sensitive to $\pm 5^{\circ}$ shifts of the east-west boundaries. The daily AWB index was defined as the average of AWB area within the selected domain, which took into account of both AWB frequency and extent. To focus on the subseasonal variability, a 7-day running mean was applied to reduce the high-frequency variability after the seasonal cycle and seasonal mean were removed (hereafter AWB index). To facilitate composite analysis, an AWB activity peak $(t=0 \mathrm{~h})$ was identified as a maximum of the AWB index anomaly exceeding 1.0 standard deviation. Composite analysis shows that positive anomalies of the AWB index start to develop around 6 days before the peak on average and decay to nearly zero 6 days after the peak (not shown). We thus defined an active AWB episode as the time period within 8 days ( \pm 4 days) of an AWB activity peak and identified 130 active AWB episodes during JASO 1985-2013. Lead and lag daily composites of atmospheric variables were constructed based on the AWB activity peaks.

\section{b. Large-scale atmospheric anomalies associated with $A W B$}

In this section, we will analyze the large-scale atmospheric anomalies associated with AWB, which has not been thoroughly investigated for the warm season before. The large-scale perspective provided by the analyses also helps shed light on the relation between TCs and AWB discussed in section 4. Figure 2 shows the composite anomalies of $200-\mathrm{hPa}$ geopotential height, sea level pressure, and $850-\mathrm{hPa}$ winds from day -4 to day +4 . A wave train spans from the western North Pacific to the North Atlantic, indicating possible upstream impacts from the North Pacific on AWB over the North Atlantic (Zhang and Wang 2018). The wave train shows a slow eastward propagation. In addition, the anomalies decay with time over the North Pacific but amplify downstream over the North Atlantic and western Europe, indicating an eastward energy dispersion
(Figs. 2a-e). Overall, the composites suggest that the wave train associated with the warm-season AWB over the North Atlantic can be traced back to the North Pacific or farther upstream.

Zooming in over the North Atlantic, there is an anomalous anticyclone at the upper troposphere over eastern North America and the North Atlantic on day -4 , with an anomalous surface low to the northwest and an anomalous surface high to the southeast (Fig. 2a). Anomalous low-level southwesterly wind occurs along the east coast of North America underneath the anomalous upper-level anticyclone. On day -2 , as the wave train propagates eastward, both the anomalous upperlevel anticyclone and the anomalous surface low over eastern North America and the North Atlantic rotate anticyclonically and then become zonally elongated (Fig. 2b). The anomalous signals start amplifying, which may be partly contributed by moist diabatic processes (Zhang and Wang 2018). On day 0, the anomalous surface low centered southeast of Greenland has extended farther eastward (Fig. 2c). Meanwhile, the anomalous upper-level trough (north of $50^{\circ} \mathrm{N}$ ) arches poleward and propagates downstream, resembling nonlinear wave reflection in the troposphere (Abatzoglou and Magnusdottir 2006). By day +2 , the wave signals over the North Atlantic remain pronounced, and the anomalous upper-level trough and the anomalous surface low around Greenland are even stronger, while the wave signals over North America become weaker (Fig. 2d). On day +4 , the anomalous upper-level ridge over the North Atlantic becomes much weaker, but the surface anomalies remain a similar intensity with a center retreating to eastern North America (Fig. 2e).

The vertical tilt structure of the wave train associated with AWB implies a modulation of vertical wind shear (VWS). Vertical wind shear is an important environmental factor for TC formation and intensity change, and also affects TC predictability (e.g., Gray 1968; DeMaria and Kaplan 1999; Rappin and Nolan 2012; Zhang and Tao 2013). Figure 3 shows the composite anomalies of VWS (defined as the magnitude of the wind vector difference between 200 and $850 \mathrm{hPa}$ ) and the 200-hPa zonal wind (U200). For brevity, we only discuss the composite anomalies over the North Atlantic sector from day -2 to day +4 below. The spatial patterns of the VWS and U200 anomalies both have a slight southwest-northeast tilt, consistent with the structure of the wave train pattern (Fig. 2). The VWS anomalies are nearly in phase with the 200-hPa zonal wind anomalies, indicating a large contribution of the upper-level wind anomalies to the VWS anomalies. The $200-\mathrm{hPa}$ zonal wind is strengthened between $45^{\circ}$ and $60^{\circ} \mathrm{N}$ and weakened between $30^{\circ}$ and $45^{\circ} \mathrm{N}$. Given the location of the 

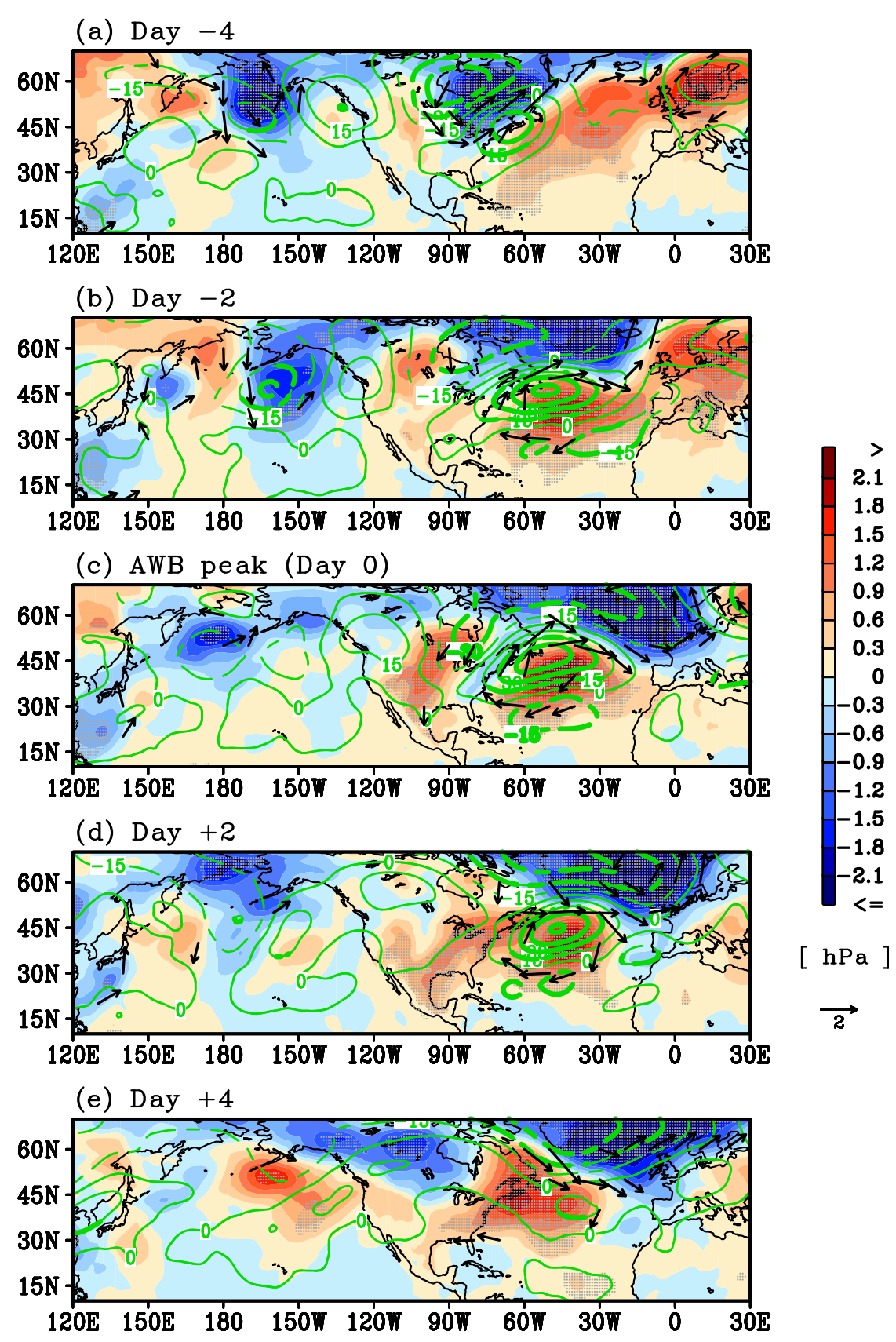

FIG. 2. Composite-mean sea level pressure anomalies (hPa; shaded; black stipples denote the $90 \%$ confidence level), 200-hPa geopotential height anomalies (gpm; thick green contours denote the $90 \%$ significance level), and anomalous $850-\mathrm{hPa}$ winds (only wind speed greater than $1 \mathrm{~m} \mathrm{~s}^{-1}$ shown in arrows) on (a) day -4 , (b) day -2 , (c) day 0 , (d) day +2 , and (e) day +4 during JASO 1985-2013. Day 0 denotes the AWB activity peaks.

long-term-mean midlatitude jet centered between $40^{\circ}$ and $50^{\circ} \mathrm{N}$ (Fig. 3), the U200 anomalies suggest a northward shift of the midlatitude jet, which is consistent with enhanced AWB through positive eddy feedback (Rivière 2009, 2010). Strong negative VWS anomalies are found along $40^{\circ} \mathrm{N}$, and positive VWS anomalies are present over the tropical-subtropical Atlantic including a large part of the main development region (MDR; Goldenberg et al. 2001). Also note that the VWS anomalies in the MDR are stronger on day +2 than day -2 , probably due to the equatorward propagation of potential vorticity anomalies resulting from AWB (Fig. 2). The 


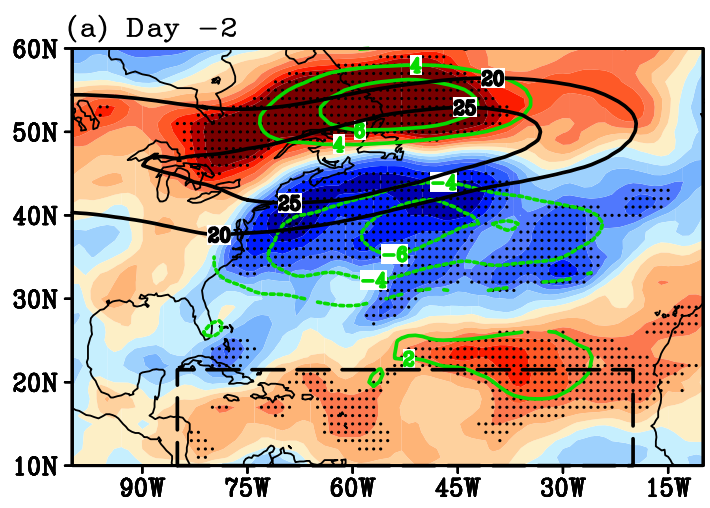

(b) AWB peak (Day 0)

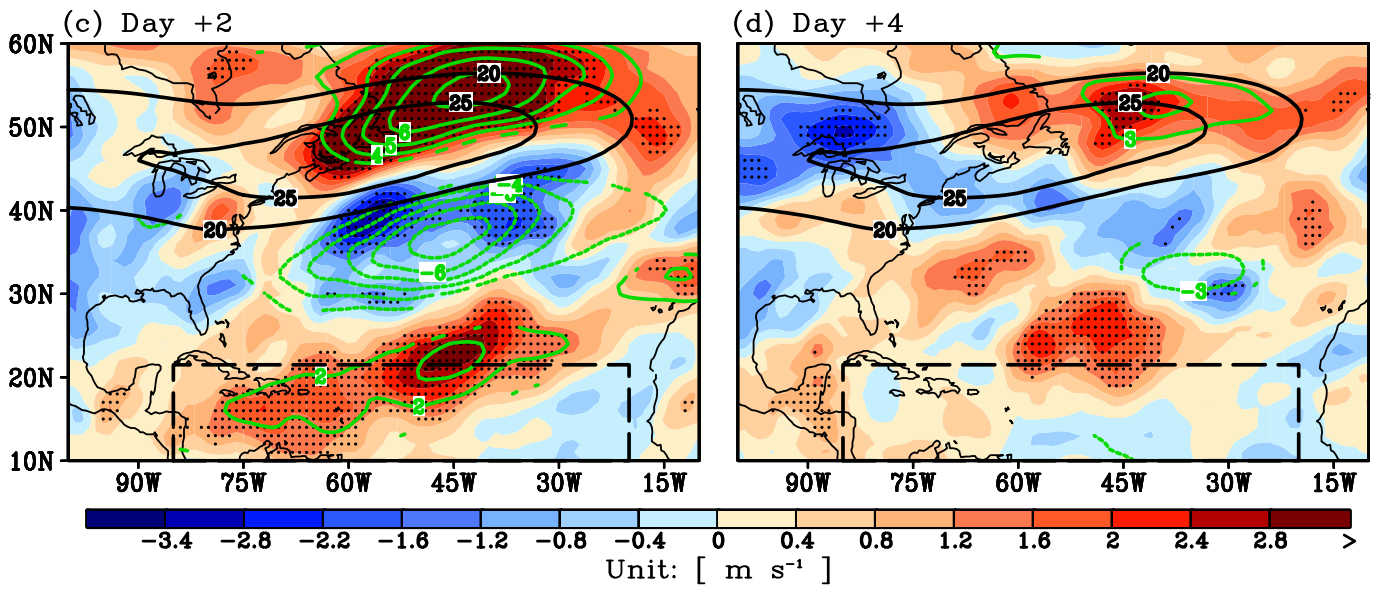

FIG. 3. Composite-mean 850-200-hPa vertical wind shear (VWS) anomalies ( $\mathrm{m} \mathrm{s}^{-1}$; shaded) and the 200-hPa zonal wind anomalies $\left(\mathrm{m} \mathrm{s}^{-1}\right.$; only significant contours above the $90 \%$ significance level shown in green) from day -2 to day +4 . Stipples denote the VWS anomalies above the $90 \%$ significance level. The black contours (climatologicalmean 200-hPa wind speed greater than $20 \mathrm{~m} \mathrm{~s}^{-1}$ during JASO 1985-2013) outline the mean state of the midlatitude jet. The black dashed box highlights the Atlantic main development region (MDR).

VWS and the upper-level zonal wind anomalies become weaker and less coherent on day +4 (Fig. 3d), consistent with the weakening upper-level geopotential height anomalies (Fig. 2d).

The variability of AWB is also linked to moisture and precipitation anomalies. Figure 4 shows the precipitable water ( $\mathrm{PW}$ ), precipitation, and $500-\mathrm{hPa}$ ascent anomalies related to AWB. From day -2 to day 0 , dry anomalies appear over the central and eastern tropical-subtropical North Atlantic (east of $\sim 75^{\circ} \mathrm{W}$; Figs. $4 \mathrm{a}, \mathrm{b}$ ), which are accompanied by enhanced sea level pressure and strengthened VWS (Figs. 2 and 3). The most obvious anomalies are the excessive wetness, enhanced precipitation, and upward motion over a southwest-northeast region from the east coast of North America to the northeastern Atlantic (30 $50^{\circ} \mathrm{N}, 85^{\circ}-45^{\circ} \mathrm{W}$ ), which persist until day +2 (Figs. $4 \mathrm{a}-\mathrm{c}$ ) and coincide with the negative VWS anomalies (Figs. 3a, b). Note that the negative moisture anomalies are slightly poleward of the positive VWS anomalies, which is also true for the positive moisture anomalies to the negative VWS anomalies. The excessive moisture along the east coast of North America is closely tied to the low-level southwesterly anomalies (Fig. 2) beneath the anomalous upper-level anticyclone, which enhances the poleward moisture transport. These features are consistent with Zhang and Wang (2018) despite the different composite methods. Zhang and Wang (2018) suggests that positive precipitation anomalies and the associated diabatic heating play an important role in amplifying the upper-level ridge and the ensuing wave breaking. Consistent with the slowly evolving wave train pattern (Fig. 2), the anomalous moisture signals show a slow southeastward propagation from day -2 to day +2 , and the western North Atlantic is characterized by positive PW anomalies from day +2 to day +4 , but the anomalies become weak and patchy on day +4 (Fig. 4d).

\section{c. $A W B$ and the $M J O$}

The link between the MJO and AWB in the warm season is investigated in this section. The MJO and the associated tropical convection anomalies can influence 


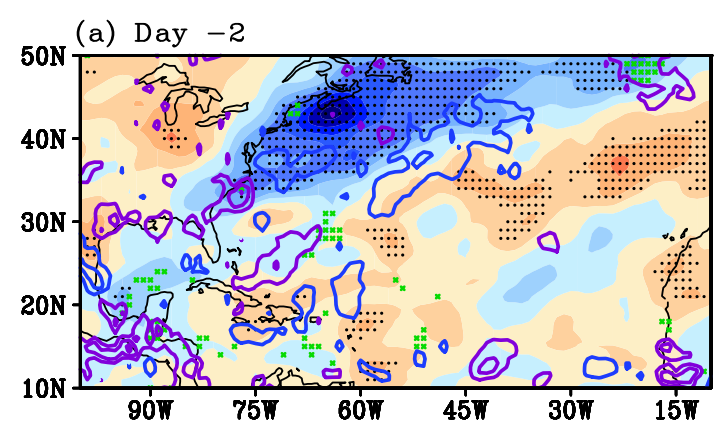

(b) AWB peak (Day 0)
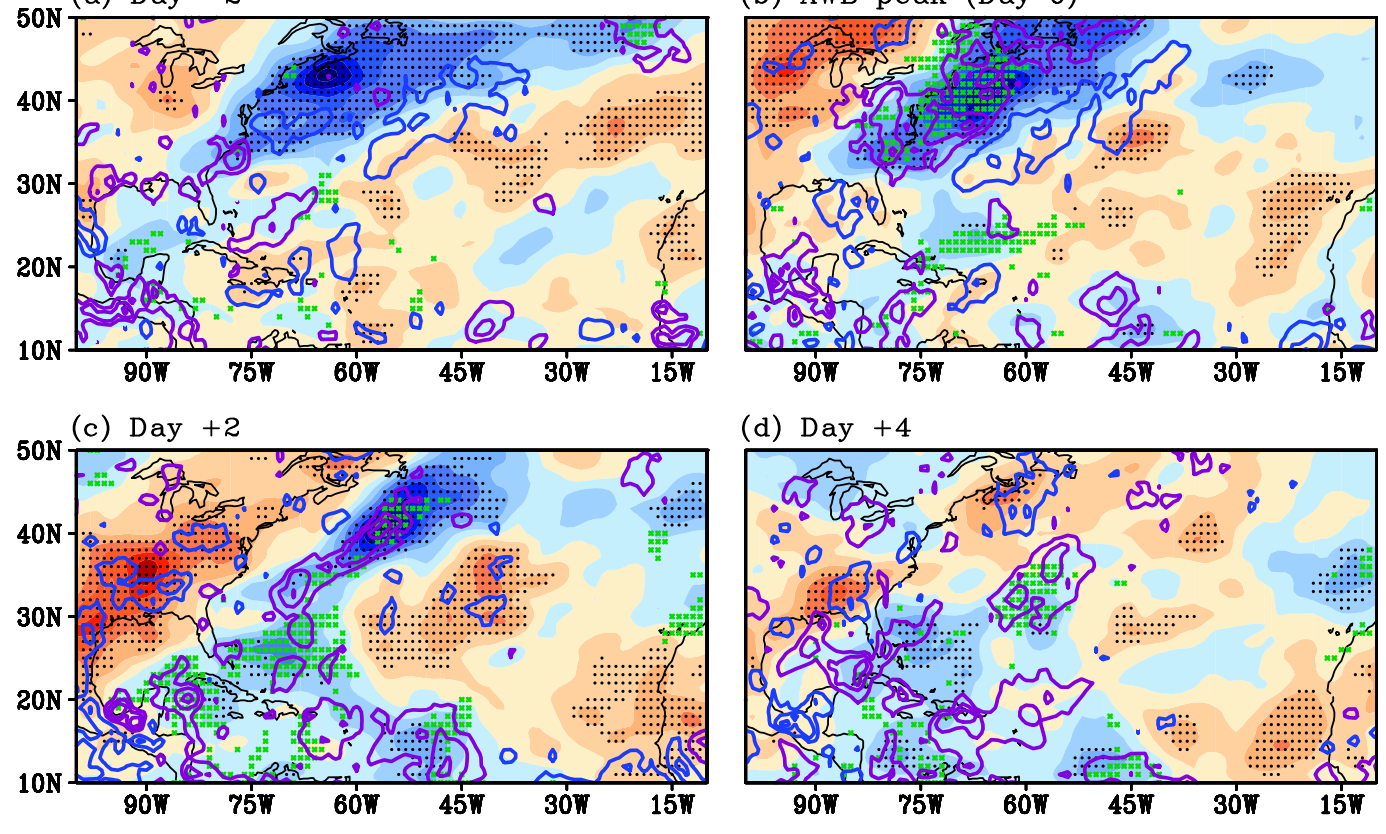

(d) Day +4
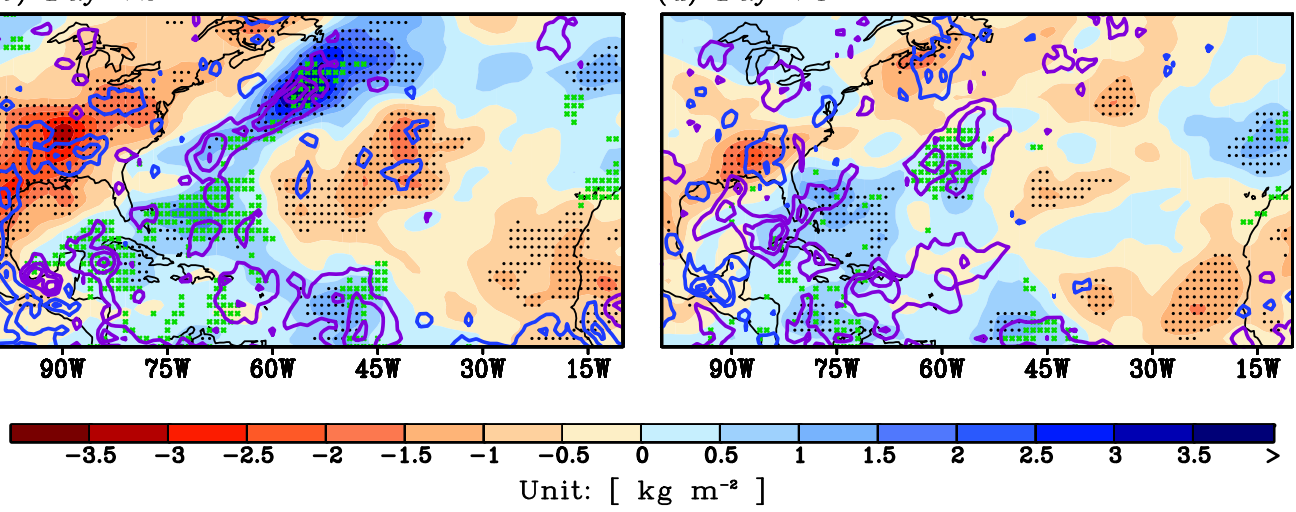

FIG. 4. As in Fig. 3, but for the precipitable water (PW) anomalies $\left(\mathrm{kg} \mathrm{m}^{-2}\right.$; shaded), the precipitation anomalies $\left[\mathrm{mm} \mathrm{day}^{-1}\right.$; purple and blue contours represent positive $\left(+1,+2,+3 \mathrm{~mm} \mathrm{day}^{-1}\right)$ and negative $\left(-3,-2,-1 \mathrm{~mm} \mathrm{day}^{-1}\right)$ values, respectively], and the $500-\mathrm{hPa}$ ascent anomalies $\left(\mathrm{Pa} \mathrm{s}^{-1}\right.$; green). The black and green stipples denote the PW and $500-\mathrm{hPa}$ ascent anomalies above the $90 \%$ confidence level, respectively.

the extratropical circulations by exciting Rossby wave trains (e.g., Matthews et al. 2004; Lukens et al. 2017), while the extratropical processes may also play a role in modulating the MJO (Ray and Li 2013). MacRitchie and Roundy (2016) suggested a two-way interaction between the MJO and AWB in boreal winter. However, the findings in winter may not be applicable in summer due to the seasonal variation of the MJO and the mean flow (e.g., Zhang and Dong 2004; Wu et al. 2006; Adames et al. 2016). A good understanding of the summertime link between the MJO and AWB helps understand the subseasonal variability of AWB and may also shed light on the relation between the MJO and TCs.

The composite anomalies of $200-\mathrm{hPa}$ geopotential height were calculated for different phases of the MJO when the RMM index amplitude exceeded 1.0. For brevity, the eight MJO phases (Wheeler and Hendon 2004) were combined into four groups based on the approximate locations of the MJO convective signals (Fig. 5). The seasonal mean and seasonal cycle were removed from the 200-hPa geopotential height field before constructing the composites.

During the MJO phases 2 and 3 (Fig. 5a), the active convection of the MJO is over the Indian Ocean
(Wheeler and Hendon 2004). A wave train pattern spans from the western Pacific warm pool across the North Pacific, then to North America. The wave train is associated with the variations of meridional geopotential gradient and the midlatitude jets. The composite $200-\mathrm{hPa}$ zonal wind anomalies (not shown) confirm that the Asian-Pacific jet is weaker and broader than the climatology, and that the jet over the eastern North Pacific and North America is stronger and narrower. Associated with the circulation anomalies are enhanced AWB over the western North Pacific and reduced AWB over the eastern North Pacific. Over the North Atlantic, AWB is enhanced north of $40^{\circ} \mathrm{N}$, reduced over the subtropical North Atlantic, and slightly enhanced farther equatorward over the central and eastern North Atlantic.

In the MJO phases 4 and 5 (Fig. $5 \mathrm{~b}$ ), the active convection of the MJO moves over the Maritime Continent. A wave train extends from East Asia, over the Arctic, to the North Atlantic, while the wave signals are very weak over the North Pacific. The midlatitude jet is weakened and broadened over the central and eastern North Pacific but is slightly enhanced over the North Atlantic (not shown). Compared to phases 2 and 3, positive AWB anomalies move eastward to the central and eastern 
(a) anom AWB area \& Z200 (MJO Phase 2+3)

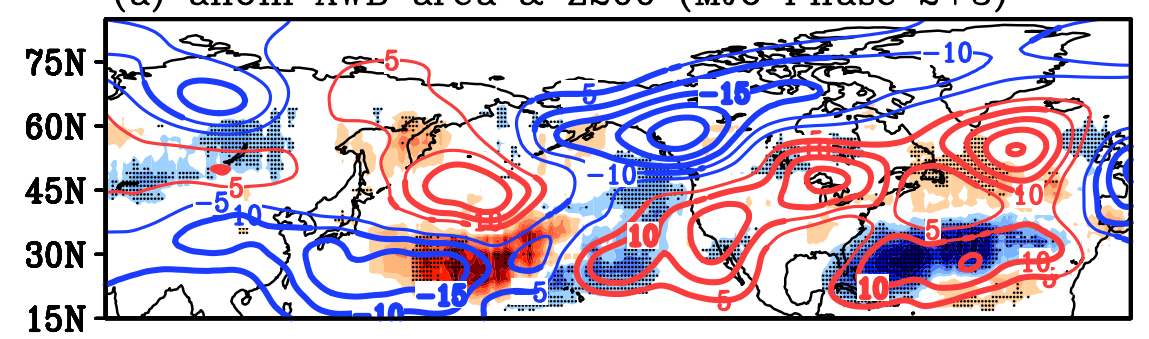

(b) anom AWB area \& Z200 (MJO Phase 4+5)

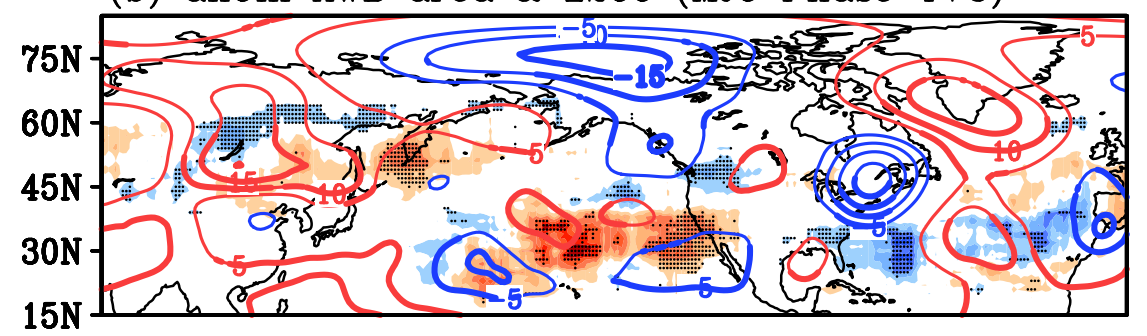

(c) anom AWB area \& Z200 (MJO Phase 6+7)

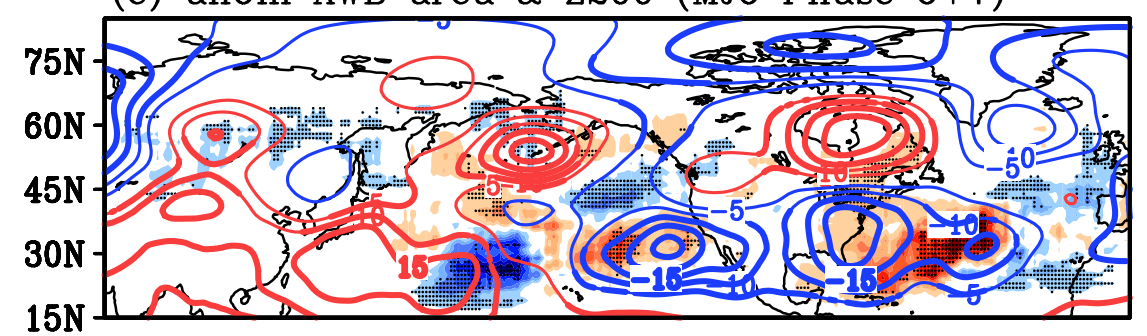

(d) anom AWB area \& Z200 (MJO Phase 8+1)
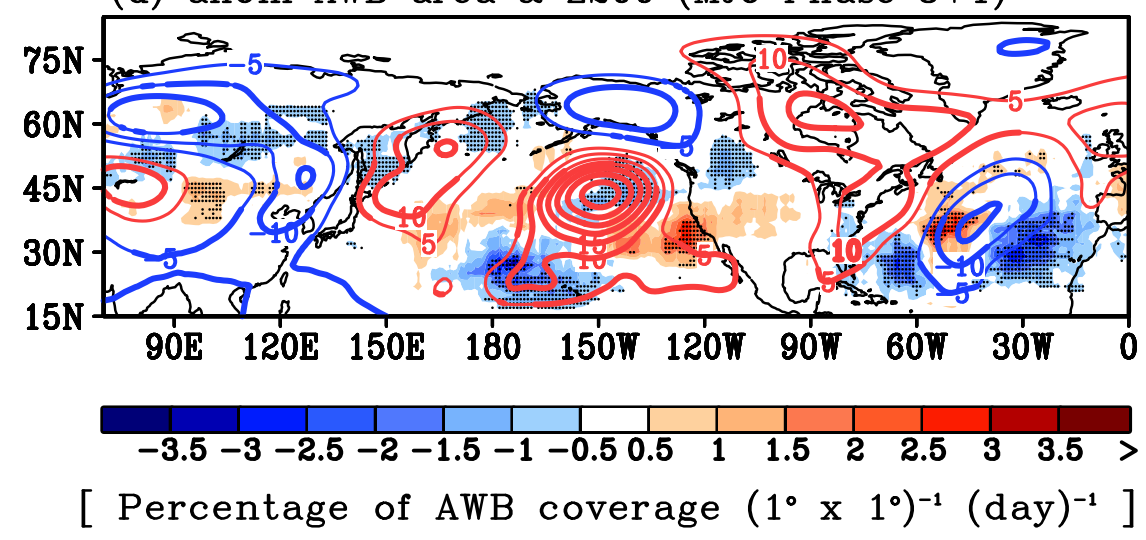

FIG. 5. Composite AWB density anomalies [percentage of AWB coverage $\left(1^{\circ} \times 1^{\circ}\right)^{-1}$ day $^{-1}$; shaded; black stipples denote the $90 \%$ confidence level] and $200-\mathrm{hPa}$ geopotential height anomalies (gpm; thick contours denote the 90\% confidence level) in the MJO (a) phases 2 and 3, (b) phases 4 and 5, (c) phases 6 and 7, and (d) phases 8 and 1 during JASO 1985-2013 with an MJO amplitude greater than 1 . The results are normalized by the number of days in each MJO phase.

North Pacific, and AWB anomalies over the North Atlantic become much weaker.

In the MJO phases 6 and 7 (Fig. 5c), the active convection of the MJO is located over the western and central Pacific, and there is no well-defined wave train pattern. But the dipole pattern over North America to the western North Atlantic indicates a weaker and broader midlatitude jet along with enhanced AWB anomalies over the western North Atlantic. Over the subtropical North Pacific, negative AWB anomalies are present near the date line with positive anomalies to the east. 
In the MJO phases 8 and 1 (Fig. $5 \mathrm{~d}$ ), the active convection of the MJO moves to the Western Hemisphere and then initiates over the Indian Ocean. A wave train pattern spans from the North Pacific to the North Atlantic. Negative AWB anomalies are still present over the central North Pacific but shift slightly eastward. The AWB anomalies over the North Atlantic become weaker and patchy with negative AWB anomalies over the subtropical western North Atlantic.

Overall, the MJO-related AWB anomalies in summer have an eastward progression along with the active convection of the MJO but do not show much similarity to their wintertime counterpart (MacRitchie and Roundy 2016). In particular, the geopotential anomalies have less coherent patterns, which can be partly attributed to the weaker and less robust MJO signals and the weaker midlatitude jets in the warm season (e.g., Zhang and Dong 2004; Adames et al. 2016). Over the tropicalsubtropical North Atlantic, AWB occurrence is reduced in the MJO phases 2 and 3 and enhanced in phases 6 and 7.

\section{Impacts of AWB on TC activity and TC prediction}

\section{a. Impacts on TC activity}

In this section, we will examine how AWB impacts Atlantic TC activity on the subseasonal time scale. The regional TC activity was quantified by the TC track density function (TDF), which was defined as the frequency of TCs during the period of interest within a $5^{\circ} \times 5^{\circ}$ box centered on each $1.0^{\circ}$ grid point (measured in TC days per year). The results were normalized by the number of days during JASO in a year with a unit of TC days per $5^{\circ} \times 5^{\circ}$ box per year to facilitate comparison.

The climatological spatial distribution of TC activity (Fig. 6a) shows that high TDF appears over the central and western MDR, the Gulf of Mexico and subtropical western North Atlantic, owing to frequent tropical cyclogeneses in these regions and the prevailing TC tracks. The AWB-related TDF resembles the climatology with one maximum near the southeast coast and another one over the central MDR, but the pattern is much patchier (Fig. 6b). Compared to the climatology, TDF is significantly reduced over most of the tropical-subtropical North Atlantic during active AWB episodes (Fig. 6c). The region of reduced TC activity is more extensive than that of strong AWB activity (Fig. 1a) or enhanced VWS (Fig. 3). It is possible that the suppressed TC genesis and/or shortened TC lifetime due to the strong VWS in the eastern and central MDR lead to the reduced TC activity downstream along the prevailing TC path.
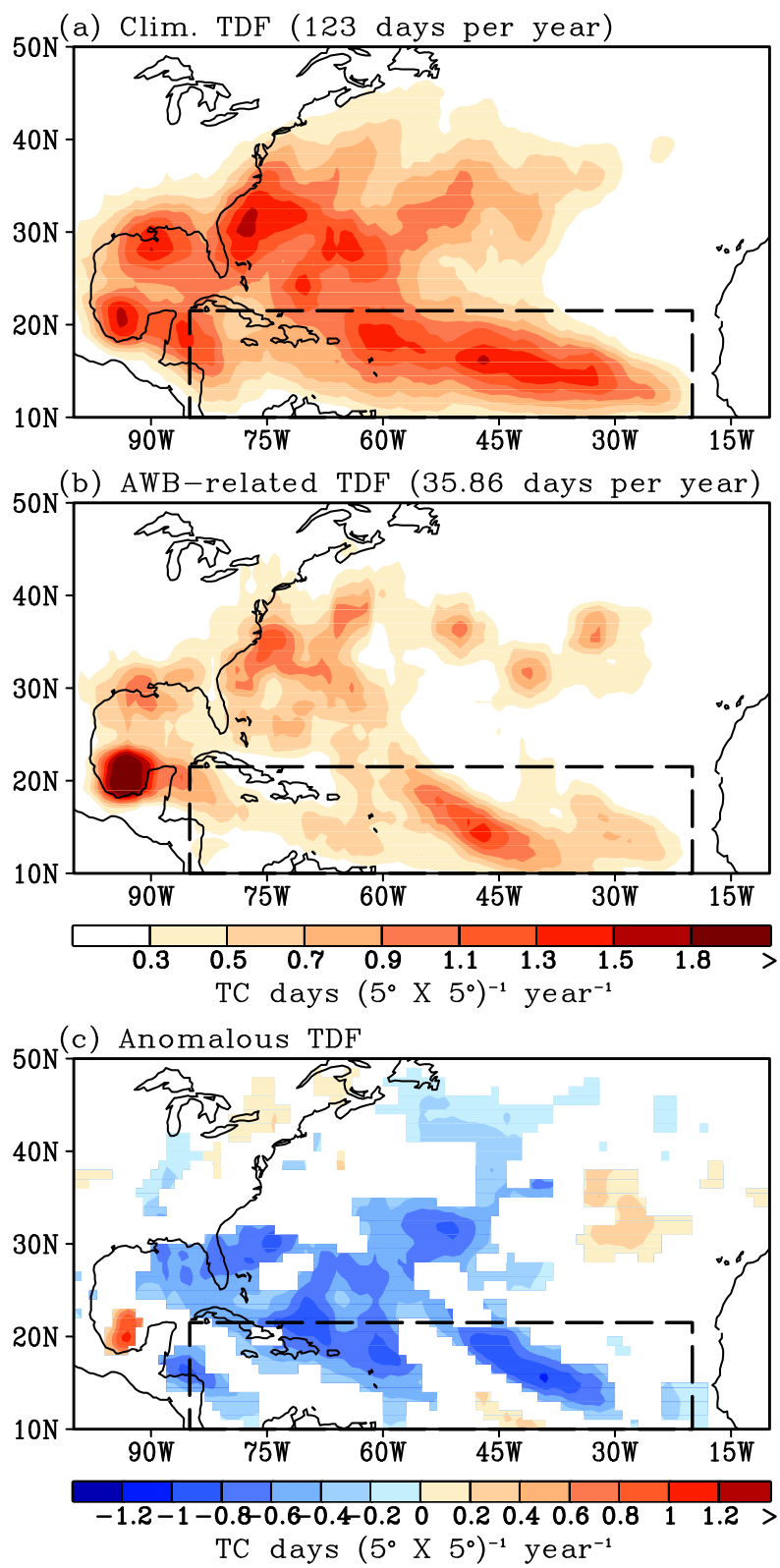

FIG. 6. Mean TC track density function [TC days $\left(5^{\circ} \times 5^{\circ}\right)^{-1} \mathrm{yr}^{-1}$ ] (a) for all Atlantic TCs during JASO 1985-2013 (climatology) and (b) for TCs during the active AWB episodes, and (c) the TC track density anomalies [(b) minus (a); only regions above the $95 \%$ confidence level are shaded]. The track density functions in (a) and (b) were normalized by the corresponding sample size (in parentheses). The black dashed box highlights the Atlantic MDR.

Meanwhile, the TC density anomalies are very weak along the east coast of North America.

To further examine the relation between AWB and TC activity, we calculated the correlations of the AWB index with the WTD and WCE indices (see the definitions of the indices in section 2). As with the AWB 
index, the seasonal cycle and the seasonal mean were removed from the TC indices to focus on the subseasonal variability of TC activity. The correlations were calculated for the warm season in each year, and the time series of the correlations are shown in Fig. 7a. The correlations are skewed toward negative values, and the mean correlations during 1985-2013 are weakly negative ( $r=-0.10$ for both WTD and WCE). Significant negative correlations are found in some years, but large fluctuations occur from year to year, which partly explain the small mean correlation coefficients. As illustrating examples, the time series of AWB, WTD and WCE in three selected years are shown in Figs. 7b-d. In 1996 and 2002, the AWB index has significant negative correlations with the WTD and WCE. The correlation coefficients are -0.37 (WTD) and -0.33 (WCE) in 1996, and -0.64 (WTD) and -0.49 (WCE) in 2002. Visual inspection reveals that a period of active TC activity from late August to early September in 1996 is associated with reduced AWB activity, and a period of reduced TC activity in mid- to late August of 2002 is coincident with active AWB. In 2011, however, significant positive correlations are found for both WTD $(r=0.33)$ and WCE $(r=0.37)$.

The large year-to-year variability of the subseasonal AWB-TC correlation may be attributed to the modulation of TC activity by other factors in addition to AWB. In particular, although active AWB tends to suppress TC activity (Fig. 6c), inactive AWB does not guarantee enhanced TC activity. Further analysis suggests that the subseasonal variations of AWB and the basinwide Atlantic TC activity tend to be negatively correlated in the years of strong MJO activity (evaluated based on the RMM index amplitude), while the correlation is much weaker in the years of weak MJO activity (not shown). Similar to the AWB-TC correlation, large interannual variability was also found in the subseasonal MJO-TC correlation in the North Atlantic (Fig. 7a). And the correlation between the local MJO index and weekly TC indices tends to be positive during the years of enhanced AWB activity and slightly negative during years of reduced AWB activity (not shown). Our finding that AWB activity reduced (enhanced) in the MJO phases 2 and 3 (6 and 7) is consistent with the early studies showing that Atlantic TC activity is enhanced (reduced) in the MJO phase 2 (7) (e.g., Klotzbach 2014). It is possible that the MJO impacts Atlantic TCs via AWB, or enhanced AWB activity helps intensify the MJO signals over the Atlantic and thus the MJO-TC correlation during certain MJO phases. However, most of these correlations are statistically insignificant, probably due to the small sample size, and this issue is thus not further discussed in this study. Nevertheless, a better understanding of the MJO-TC-AWB relation will provide new insights into the subseasonal variability and predictability of Atlantic TC activity.

\section{b. Impacts on TC subseasonal prediction}

In this section, we will investigate how AWB impacts the predictability of TCs by evaluating the predictive skill of the GEFS reforecasts. As a nonlinear, synopticscale, extratropical phenomenon, AWB may limit the TC predictability. For example, Fitzpatrick et al. (1995) showed that model biases in predicting TUTT (often associated with RWB) can reduce the TC forecasting skill. In a recent study, Wang et al. (2018) examined the predictability of tropical cyclogenesis for five tropical cyclogenesis pathways (McTaggart-Cowan et al. 2013) over the Atlantic and found that the strong and weak tropical-transition pathways were associated with lower predictability than the other pathways. The lower predictability can be attributed to the stronger extratropical influence involved in TC formation for the tropicaltransition pathways, which often takes the form of an upper-level trough or TUTT cells related to AWB (Davis and Bosart 2004). The extratropical atmosphere is generally less predictable than the tropical atmosphere beyond the time scale of a few days due to the active upscale energy cascade in the extratropics and the strong atmosphere-ocean coupling in the tropics (e.g., Charney and Shukla 1981; Palmer 1996).

Here we evaluated the predictive skill of tropical cyclogenesis in terms of hit rate using Eq. (1) and compared the predictive skill of tropical cyclogenesis during active AWB episodes with the long-term-mean hit rate. Among the 130 active AWB episodes, 48 episodes are associated with tropical cyclogenesis (hereafter the AWBrelated TCs). As shown in Fig. 8, the hit rate of the AWBrelated TCs is lower than the long-term-mean hit rate of all TCs during JASO 1985-2013. Although the hit-rate difference exceeds the $5 \%$ significance level only on days $2-3$ based on the 5th percentile of the 10000 bootstrap estimates, the lower predictive skill of the AWB-related TCs is consistent with the lower predictability of large-scale environmental conditions. The predictability of a variable is often measured by ensemble spread. Figure 9 shows the ensemble spread of VWS, PW, and 850-hPa relative vorticity $\left(\right.$ Zeta $\left._{850}\right)$, which are calculated at the observed TC genesis time over a $20^{\circ} \times 20^{\circ}$ box centered at the TC genesis location. All the three variables have larger ensemble spread (lower predictability) than long-term-mean ensemble spread when TCs occur during active AWB episodes, and the differences increase with the forecast lead times. This suggests that AWB may affect the predictability of TC formations despite the lack of significance in Fig. 8. 
(a) Subseasonal Corr (TC vs AWB, TC vs MJO)

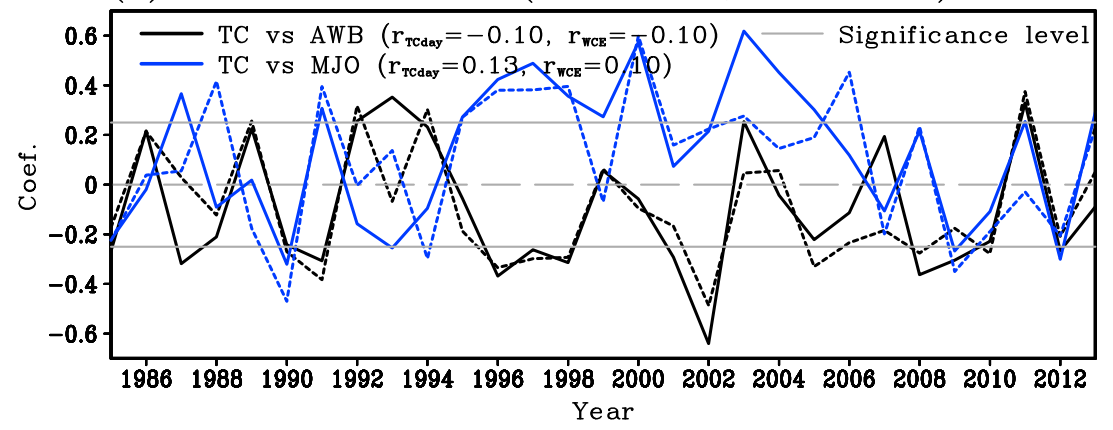

(b) Year 1996

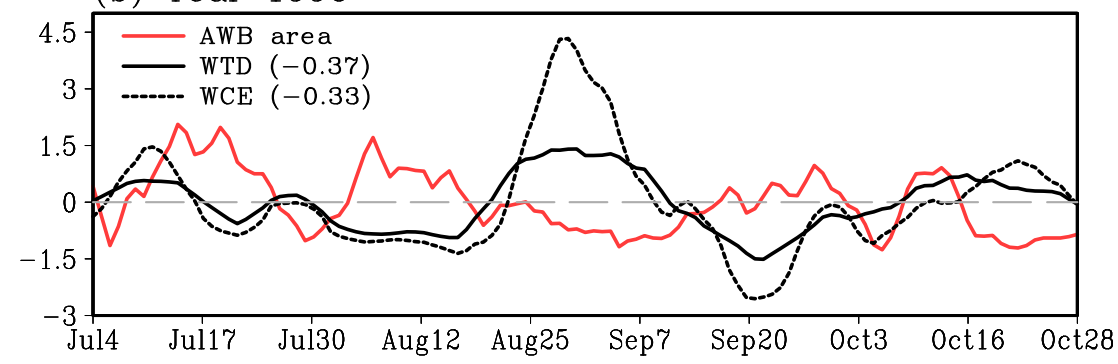

(c) Year 2002
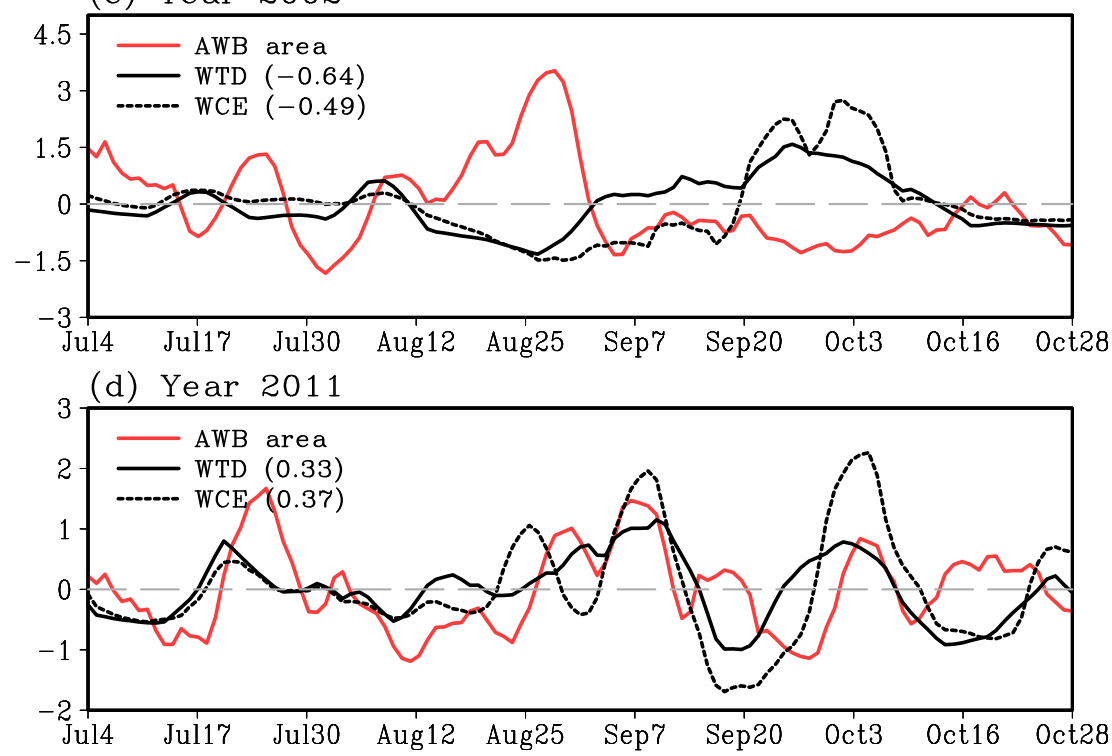

FIG. 7. (a) Time series of the Pearson correlations of the weekly TC days (WTD; days; solid) and the weekly cyclone energy (WCE; $10^{4} \mathrm{kt}^{2}$; dashed) with the AWB index (black) and the weekly local MJO index (blue) for each year during JASO 1985-2013. The mean correlations are marked in the top-left corner of each plot. The gray lines indicate the significance level using a two-tailed $t$ test at the $90 \%$ confidence level, and the degree of freedom is adjusted using a "modified" Chelton method (Pyper and Peterman 1998). (b)-(d) The WTD (black solid) and the WCE (black dashed) against the AWB index (red) in 1996, 2002, and 2011, respectively.

The subseasonal predictability of TC activity was assessed by the model skill in capturing the active and inactive TC periods within a season using the GEFS reforecasts. As in Li et al. (2016), we calculated the subseasonal correlations of the weekly TC indices between the GEFS and the IBTrACS in each year (Figs. 10a,b).
The GEFS has a reasonable skill in capturing the TC subseasonal variations with a forecast lead time up to 2 weeks. The mean correlations for WTD (WCE) are $0.64(0.74)$ and $0.42(0.49)$ for the week-1 and the week-2 reforecasts, respectively. When the subseasonal correlations are stratified by the seasonal-mean AWB index, 


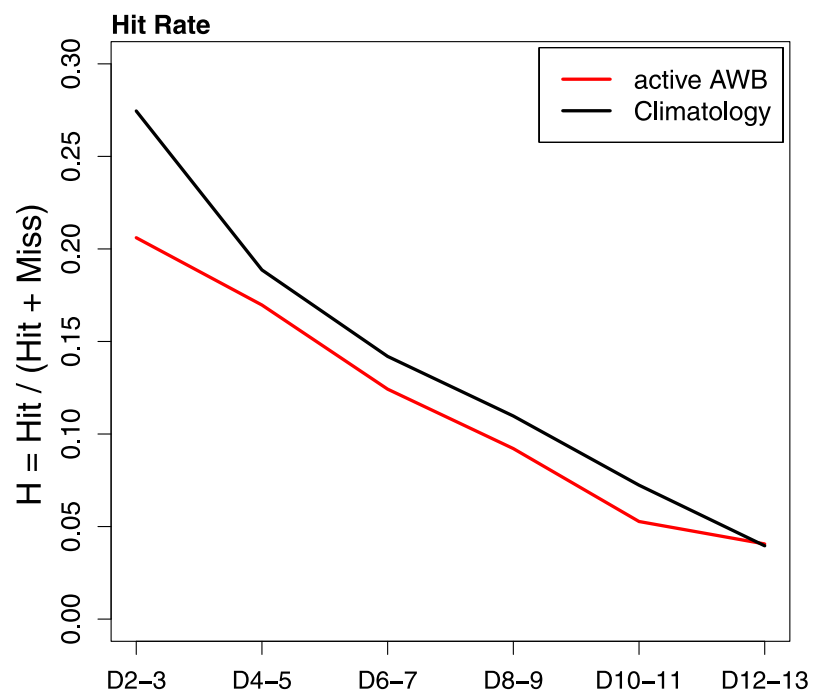

FIG. 8. Ensemble-mean hit rate of all the Atlantic TCs during JASO 1985-2013 (black solid) and that of the AWB-related TCs (red solid) in the GEFS reforecasts.

Fig. 10c indicates that the model has lower (higher) predictive skill of TC subseasonal variations in the years of enhanced (reduced) AWB activity for both the week-1 and week-2 reforecasts. Again, the lower subseasonal predictive skill of TC activity indicates reduced predictability and can be attributed to stronger extratropical influence owing to enhanced AWB activity.

\section{Summary}

The subseasonal variability of AWB and its impacts on the large-scale atmospheric condition and TC activity were investigated during the Atlantic warm season
(July-October) from 1985 to 2013 (29 years). The analyses show that AWB modulates both the upper- and lower-tropospheric circulations and is associated with the variability of vertical wind shear, tropospheric humidity, and precipitation on the subseasonal time scale. The atmospheric circulation anomalies are related to a Rossby wave train spanning from the North Pacific to the North Atlantic. Statistically significant anomalies are found within 8 days ( \pm 4 days) of an AWB activity peak, which may lead to suppressed TC activity over the Atlantic central and western MDR and the subtropical western North Atlantic, especially along the climatological TUTT region. The subseasonal correlations between the AWB index and TC indices vary strongly from year to year, and significant negative correlations exist only in some years.

Composite analysis revealed anomalies of AWB activity associated with the MJO. More specifically, AWB occurrence over the tropical-subtropical west Atlantic is reduced in phases 2 and 3 and enhanced in phases 6 and 7 based on the RMM index. However, the teleconnection patterns associated with the MJO in boreal summer are not very coherent, and the dynamic mechanisms between the MJO and AWB are unclear. In particular, it is not clear whether the MJO modulates AWB activity or whether the MJO affects Atlantic TC activity via AWB. Numerical model simulations may help clarify the MJO-TC-AWB relation and provide new insights into the subseasonal variability and predictability of the Atlantic TCs, which are beyond the scope of this study.

The impacts of AWB on the Atlantic TC prediction were investigated using the NCEP GEFS reforecasts. The GEFS exhibits a lower hit rate of TC genesis during
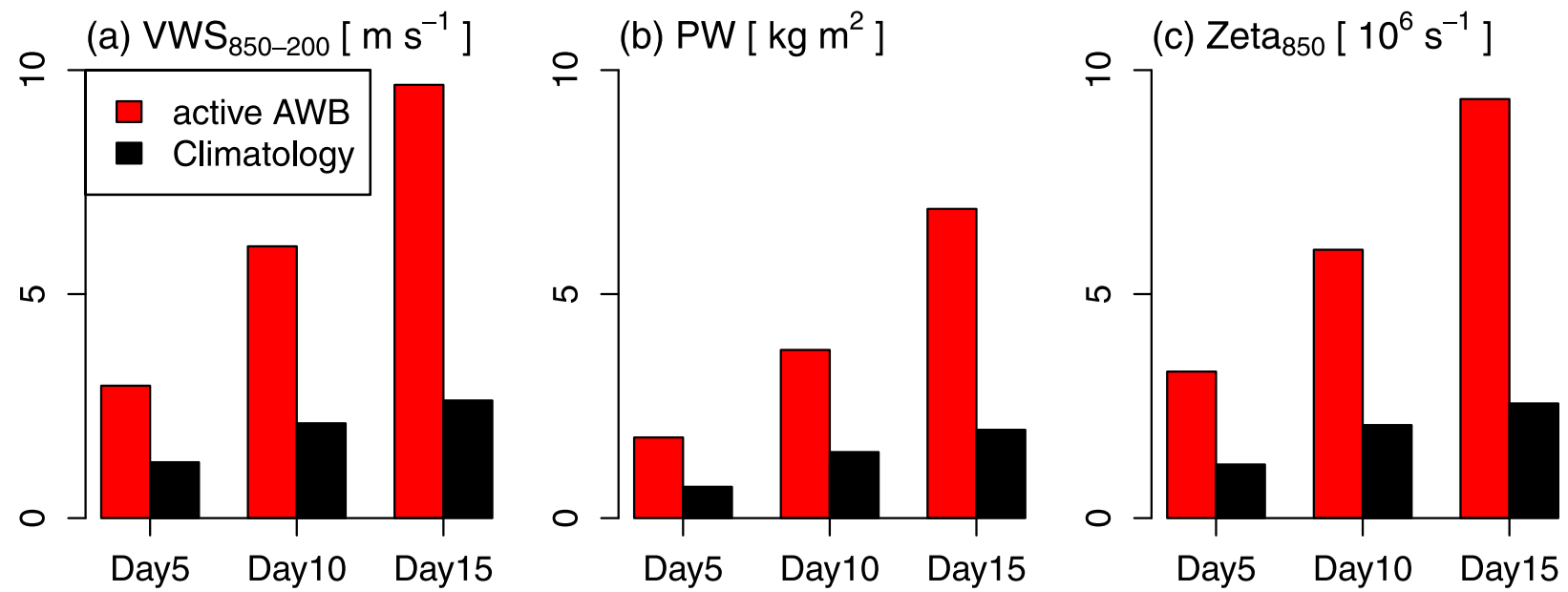

FIG. 9. Ensemble spread of the ambient (a) vertical wind shear $\left(\mathrm{VWS}_{850-200} ; \mathrm{m} \mathrm{s}^{-1}\right)$, (b) the precipitable water $\left(\mathrm{PW} ; \mathrm{kg} \mathrm{m}^{-2}\right)$, and (c) 850-hPa relative vorticity (Zeta $850 ; 10^{6} \mathrm{~s}^{-1}$ ) for all Atlantic TCs (black) and the AWB-related TCs (red) during JASO $1985-2013$ in the GEFS reforecasts. All differences between two groups are significant at the $95 \%$ confidence level. 
(a) Subseasonal Correlation of WTD with IBTrACS

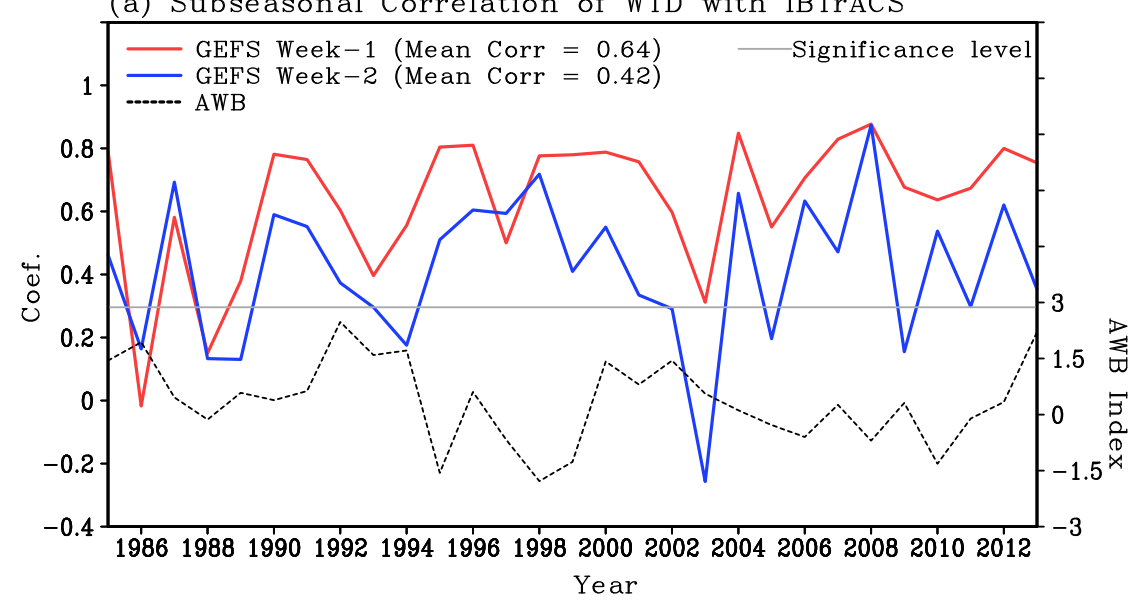

(b) Subseasonal Correlation of WCE with IBTrACS

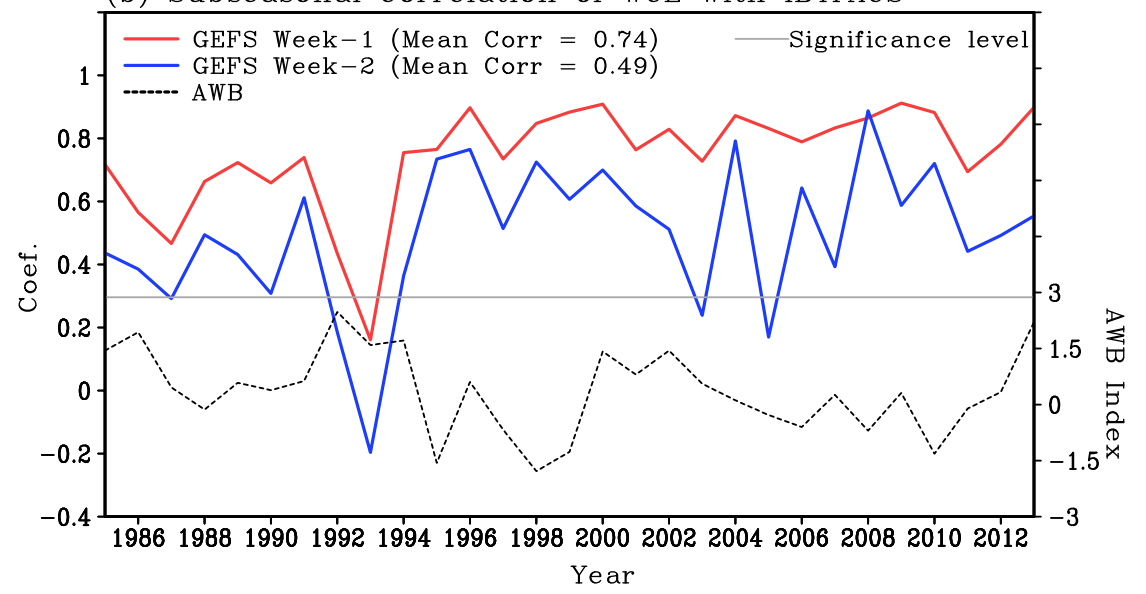

(c) WTD (AWB; $\pm 1 \mathrm{SD})$

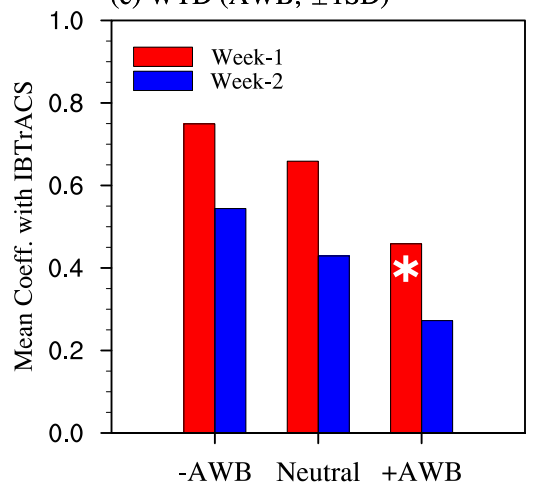

(d) WCE (AWB; $\pm 1 \mathrm{SD})$

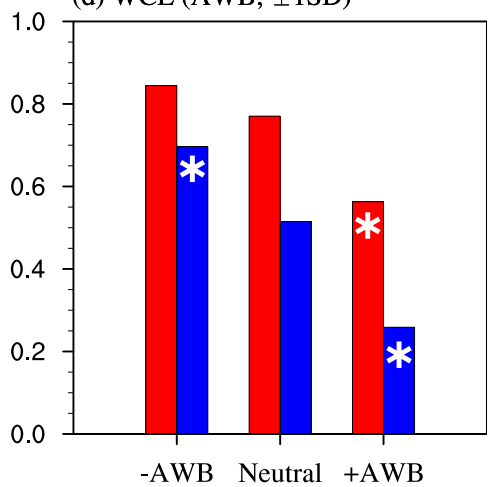

FIG. 10. Subseasonal correlations of the (a) WTD and (b) WCE between the GEFS reforecasts (red for week 1 and blue for week 2) and the observation. The seasonal (JASO)mean AWB index is represented by the dashed black line. The mean correlation coefficients during 1985-2013 are listed in parentheses with the panel legends. The gray lines denote the $95 \%$ confidence level. (c),(d) The correlation coefficients are stratified into three groups based on the seasonal-mean AWB index for (c) WTD and (d) WCE. The asterisks denote the differences above the $95 \%$ confidence level between an anomalous group $(<-1.0$ or $>1.0$ std $\mathrm{dev}$ ) and the neutral group (from -1.0 to $1.0 \mathrm{std} \mathrm{dev}$ ) using a two-tailed $t$ test. The degree of freedom is adjusted using a "modified Chelton" method. 
the active AWB episodes than the long-term-mean hit rate, which is consistent with the lower predictability of the ambient vertical wind shear, tropospheric humidity, and low-level relative vorticity. The result is also consistent with Wang et al.'s (2018) finding that tropical cyclogenesis pathways subject to stronger extratropical influence are associated with lower predictability. In addition, the GEFS is less skillful in capturing the active and inactive TC periods within a season when AWB activity is enhanced, which suggests that active AWB tends to reduce TC predictability on the subseasonal time scale.

This study emphasizes the impacts of AWB on TCs over the Atlantic. Recent studies suggested that recurving TCs may induce amplified Rossby wave trains and Rossby wave breaking downstream (e.g., Bi et al. 2015; Riemer and Jones 2014; Archambault et al. 2015; Quinting and Jones 2016). An integrated, global picture of the complex interaction among the MJO, TCs, and Rossby wave breaking will help better understand the variability and predictability of tropical weather and climate systems on the subseasonal time scale.

Acknowledgments. This work is supported by the NOAA Grants NA15NWS4680007 and NA16OAR4310080, ONR Grant N00014-18-1-2216, and the UIUC Graduate College 2016-17 Dissertation Fellowship awarded to WL. The GEFS reforecasts are available at http://esrl.noaa.gov/psd/forecasts/ reforecast 2 . The computing resources and other datasets are provided by the CISL at NCAR.

\section{REFERENCES}

Abatzoglou, J. T., and G. Magnusdottir, 2006: Planetary wave breaking and nonlinear reflection: Seasonal cycle and interannual variability. J. Climate, 19, 6139-6152, https://doi.org/ 10.1175/JCLI3968.1.

Adames, Á. F., J. M. Wallace, and J. M. Monteiro, 2016: Seasonality of the structure and propagation characteristics of the MJO. J. Atmos. Sci., 73, 3511-3526, https://doi.org/10.1175/ JAS-D-15-0232.1.

Archambault, H. M., D. Keyser, L. F. Bosart, C. A. Davis, and J. M. Cordeira, 2015: A composite perspective of the extratropical flow response to recurving western North Pacific tropical cyclones. Mon. Wea. Rev., 143, 1122-1141, https://doi.org/ 10.1175/MWR-D-14-00270.1.

Belanger, J. I., J. A. Curry, and P. J. Webster, 2010: Predictability of North Atlantic tropical cyclone activity on intraseasonal time scales. Mon. Wea. Rev., 138, 4362-4374, https://doi.org/ 10.1175/2010MWR3460.1.

Bell, G. D., and Coauthors, 2000: Climate assessment for 1999. Bull. Amer. Meteor. Soc., 81, S1-S50, https://doi.org/10.1175/ 1520-0477(2000)81[s1:CAF]2.0.CO;2.

Benedict, J. J., S. Lee, and S. B. Feldstein, 2004: Synoptic view of the North Atlantic Oscillation. J. Atmos. Sci., 61, 121-144, https://doi.org/10.1175/1520-0469(2004)061<0121: SVOTNA $>2.0 . \mathrm{CO} ; 2$.
Bentley, A. M., L. F. Bosart, and D. Keyser, 2017: Uppertropospheric precursors to the formation of subtropical cyclones that undergo tropical transition in the North Atlantic basin. Mon. Wea. Rev., 145, 503-520, https://doi.org/10.1175/ MWR-D-16-0263.1.

Bi, M., T. Li, M. Peng, and X. Shen, 2015: Interactions between Typhoon Megi (2010) and a low-frequency monsoon gyre. J. Atmos. Sci., 72, 2682-2702, https://doi.org/10.1175/JAS-D-14-0269.1.

Cassou, C., 2008: Intraseasonal interaction between the MaddenJulian oscillation and the North Atlantic Oscillation. Nature, 455, 523-527, https://doi.org/10.1038/nature07286.

Charney, J. G., and J. Shukla, 1981: Predictability of monsoons. Monsoon Dynamics, J. Lighthill and R. Pearce, Eds., Cambridge University Press, 99-110.

Davis, C. A., and L. F. Bosart, 2004: The TT problem: Forecasting the tropical transition of cyclones. Bull. Amer. Meteor. Soc., 85, 1657-1662, https://journals.ametsoc.org/doi/pdf/10.1175/ BAMS-85-11-1657.

Dee, D., and Coauthors, 2011: The ERA-Interim Reanalysis: Configuration and performance of the data assimilation system. Quart. J. Roy. Meteor. Soc., 137, 553-597, https://doi.org/ 10.1002/qj.828.

DeMaria, M., and J. Kaplan, 1999: An updated Statistical Hurricane Intensity Prediction Scheme (SHIPS) for the Atlantic and eastern North Pacific basins. Wea. Forecasting, 14, 326-337, https://doi.org/10.1175/1520-0434(1999)014<0326: AUSHIP $>2.0 . \mathrm{CO} ; 2$.

de Vries, A. J., S. B. Feldstein, M. Riemer, E. Tyrlis, M. Sprenger, M. Baumgart, M. Fnais, and J. Lelieveld, 2016: Dynamics of tropical-extratropical interactions and extreme precipitation events in Saudi Arabia in autumn, winter and spring. Quart. J. Roy. Meteor. Soc., 142, 1862-1880, https://doi.org/10.1002/qj.2781.

Elsberry, R. L., H.-C. Tsai, and M. S. Jordan, 2014: Extended-range forecasts of Atlantic tropical cyclone events during 2012 using the ECMWF 32-day ensemble predictions. Wea. Forecasting, 29, 271-288, https://doi.org/10.1175/WAF-D-13-00104.1.

Fitzpatrick, P. J., J. A. Knaff, C. W. Landsea, and S. V. Finley, 1995: Documentation of a systematic bias in the aviation model's forecast of the Atlantic tropical upper-tropospheric trough: Implications for tropical cyclone forecasting. Wea. Forecasting, 10, 433-446, https://doi.org/10.1175/1520-0434(1995)010<0433: DOASBI $>2.0 . \mathrm{CO} ; 2$.

Franzke, C., S. B. Feldstein, and S. Lee, 2011: Synoptic analysis of the Pacific-North American teleconnection pattern. Quart. J. Roy. Meteor. Soc., 137, 329-346, https://doi.org/10.1002/ qj.768.

Gabriel, A., and D. Peters, 2008: A diagnostic study of different types of Rossby wave breaking events in the northern extratropics. J. Meteor. Soc. Japan, 86, 613-631, https://doi.org/ 10.2151/jmsj.86.613.

Galarneau, T. J., Jr., R. McTaggart-Cowan, L. F. Bosart, and C. A. Davis, 2015: Development of North Atlantic tropical disturbances near upper-level potential vorticity streamers. J. Atmos. Sci., 72, 572-597, https://doi.org/10.1175/JAS-D-14-0106.1.

Goldenberg, S. B., C. W. Landsea, A. M. Mestas-Nuñez, and W. M. Gray, 2001: The recent increase in Atlantic hurricane activity: Causes and implications. Science, 293, 474-479, https://doi.org/ 10.1126/science. 1060040 .

Gray, W. M., 1968: Global view of the origin of tropical disturbances and storms. Mon. Wea. Rev., 96, 669-700, https://doi.org/ 10.1175/1520-0493(1968)096<0669:GVOTOO > 2.0.CO;2.

Halperin, D. J., H. E. Fuelberg, R. E. Hart, J. H. Cossuth, P. Sura, and R. J. Pasch, 2013: An evaluation of tropical cyclone genesis 
forecasts from global numerical models. Wea. Forecasting, 28, 1423-1445, https://doi.org/10.1175/WAF-D-13-00008.1.

Hamill, T. M., G. T. Bates, J. S. Whitaker, D. R. Murray, M. Fiorino, T. J. Galarneau Jr., Y. Zhu, and W. Lapenta, 2013: NOAA's second-generation global medium-range ensemble reforecast dataset. Bull. Amer. Meteor. Soc., 94, 1553-1565, https://doi.org/10.1175/BAMS-D-12-00014.1.

Hu, H., F. Dominguez, Z. Wang, D. A. Lavers, G. Zhang, and F. M. Ralph, 2017: Linking atmospheric river hydrological impacts on the U.S. West Coast to Rossby wave breaking. J. Climate, 30, 3381-3399, https://doi.org/10.1175/JCLI-D-16-0386.1.

Huffman, G. J., R. F. Adler, M. Morrissey, D. T. Bolvin, S. Curtis, R. Joyce, B. McGavock, and J. Susskind, 2001: Global precipitation at one-degree daily resolution from multi-satellite observations. J. Hydrometeor., 2, 36-50, https://doi.org/10.1175/ 1525-7541(2001)002<0036:GPAODD>2.0.CO;2.

Kleist, D. T., D. F. Parrish, J. C. Derber, R. Treadon, W. Wu, and S. Lord, 2009: Introduction of the GSI into the NCEP Global Data Assimilation System. Wea. Forecasting, 24, 1691-1705, https://doi.org/10.1175/2009WAF2222201.1.

Klotzbach, P. J., 2014: The Madden-Julian oscillation's impacts on worldwide tropical cyclone activity. J. Climate, 27, 2317-2330, https://doi.org/10.1175/JCLI-D-13-00483.1.

— cyclone activity by the Madden-Julian oscillation (MJO) from 1905 to 2011. J. Climate, 28, 204-217, https://doi.org/10.1175/ JCLI-D-14-00509.1.

Knapp, K. R., M. C. Kruk, D. H. Levinson, H. J. Diamond, and C. J. Neumann, 2010: The International Best Track Archive for Climate Stewardship (IBTrACS) unifying tropical cyclone data. Bull. Amer. Meteor. Soc., 91, 363-376, https://doi.org/ 10.1175/2009BAMS2755.1.

Leroy, A., and M. C. Wheeler, 2008: Statistical prediction of weekly tropical cyclone activity in the Southern Hemisphere. Mon. Wea. Rev., 136, 3637-3654, https://doi.org/10.1175/ 2008MWR2426.1.

Li, W., Z. Wang, M. S. Peng, and J. A. Ridout, 2014: Evaluation of tropical intraseasonal variability and moist processes in the NOGAPS analysis and short-term forecasts. Wea. Forecasting, 29, 975-995, https://doi.org/10.1175/WAF-D-14-00010.1.

,-- , and,- 2016 : Evaluating tropical cyclone forecasts from the NCEP Global Ensemble Forecasting System (GEFS) Reforecast version 2. Wea. Forecasting, 31, 895-916, https:// doi.org/10.1175/WAF-D-15-0176.1.

Liu, C., and E. A. Barnes, 2015: Extreme moisture transport into the Arctic linked to Rossby wave breaking. J. Geophys. Res. Atmos., 120, 3774-3788, https://doi.org/10.1002/2014JD022796.

Lukens, K. E., S. B. Feldstein, C. Yoo, and S. Lee, 2017: The dynamics of the extratropical response to Madden-Julian oscillation convection. Quart. J. Roy. Meteor. Soc., 143, 1095-1106, https://doi.org/10.1002/qj.2993.

MacRitchie, K., and P. E. Roundy, 2016: The two-way relationship between the Madden-Julian oscillation and anticyclonic wave breaking. Quart. J. Roy. Meteor. Soc., 142, 2159-2167, https:// doi.org/10.1002/qj.2809.

Madden, R. A., and P. R. Julian, 1972: Description of globalscale circulation cells in the tropics with a 40-50 day period. J. Atmos. Sci., 29, 1109-1123, https://doi.org/10.1175/ 1520-0469(1972)029<1109:DOGSCC>2.0.CO;2.

Maloney, E. D., and D. L. Hartmann, 2000: Modulation of hurricane activity in the Gulf of Mexico by the Madden-Julian oscillation. Science, 287, 2002-2004, https://doi.org/10.1126/ science.287.5460.2002.
Marchok, T. P., 2002: How the NCEP tropical cyclone tracker works. Preprints, 25th Conf. on Hurricanes and Tropical Meteorology, San Diego, CA, Amer. Meteor. Soc., P1.13, https:// ams.confex.com/ams/25HURR/techprogram/paper_37628.htm.

Martius, O. O., C. C. Schwierz, and H. C. Davies, 2007: Breaking waves at the tropopause in the wintertime Northern Hemisphere: Climatological analyses of the orientation and the theoretical LC1/2 classification. J. Atmos. Sci., 64, 2576-2592, https://doi.org/10.1175/JAS3977.1.

Matthews, A. J., B. J. Hoskins, and M. Masutani, 2004: The global response to tropical heating in the Madden-Julian oscillation during the northern winter. Quart. J. Roy. Meteor. Soc., 130, 1991-2011, https://doi.org/10.1256/qj.02.123.

McIntyre, M. E., and T. N. Palmer, 1983: Breaking planetary waves in the stratosphere. Nature, 305, 593-600, https://doi.org/ 10.1038/305593a0.

— breaking for Rossby and gravity waves. Pure Appl. Geophys., 123, 964-975, https://doi.org/10.1007/BF00876984.

McTaggart-Cowan, R., T. J. Galarneau Jr., L. F. Bosart, R. W. Moore, and O. Martius, 2013: A global climatology of baroclinically influenced tropical cyclogenesis. Mon. Wea. Rev., 141, 1963-1989, https://doi.org/10.1175/MWR-D-12-00186.1.

Michel, C., and G. Rivière, 2011: The link between Rossby wave breakings and weather regime transitions. J. Atmos. Sci., 68 , 1730-1748, https://doi.org/10.1175/2011JAS3635.1.

Moore, R. W., O. Martius, and T. Spengler, 2010: The modulation of the subtropical and extratropical atmosphere in the Pacific basin in response to the Madden-Julian oscillation. Mon. Wea. Rev., 138, 2761-2779, https://doi.org/10.1175/2010MWR3194.1.

National Academies of Sciences, Engineering, and Medicine, 2016: Next Generation Earth System Prediction: Strategies for Subseasonal to Seasonal Forecasts. National Academies Press, $350 \mathrm{pp}$.

Palmer, T. N., 1996: Predictability of the atmosphere and oceans: From days to decades. Decadal Climate Variability: Dynamics and Predictability, D. L. T. Anderson and J. Willebrand, Eds., NATO ASI Series, Vol. 44, Springer, 83-155.

Papin, P. P., 2017: Variations in potential vorticity streamer activity: Development pathways, environmental impacts, and links to tropical cyclone activity in the North Atlantic basin. $\mathrm{Ph} . \mathrm{D}$ thesis, University at Albany, State University of New York, $225 \mathrm{pp}$.

Payne, A. E., and G. Magnusdottir, 2014: Dynamics of landfalling atmospheric rivers over the North Pacific in 30 years of MERRA reanalysis. J. Climate, 27, 7133-7150, https://doi.org/ 10.1175/JCLI-D-14-00034.1.

Peters, D., and D. W. Waugh, 1996: Influence of barotropic shear on the poleward advection of upper-tropospheric air. J. Atmos. Sci., $\mathbf{5 3}$, 3013-3031, https://doi.org/10.1175/1520-0469(1996)053<3013: IOBSOT $>2.0 . \mathrm{CO} ; 2$.

Postel, G. A., and M. H. Hitchman, 1999: A climatology of Rossby wave breaking along the subtropical tropopause. J. Atmos. Sci., 56, 359-373, https://doi.org/10.1175/1520-0469(1999)056<0359: ACORWB $>2.0 . C O ; 2$.

Pyper, B. J., and R. M. Peterman, 1998: Comparison of methods to account for autocorrelation in correlation analyses of fish data. Can. J. Fish. Aquat. Sci., 55, 2127-2140, https://doi.org/10.1139/ f98-104.

Quinting, J. F., and S. C. Jones, 2016: On the impact of tropical cyclones on Rossby wave packets: A climatological perspective. Mon. Wea. Rev., 144, 2021-2048, https://doi.org/10.1175/ MWR-D-14-00298.1. 
Rappin, E. D., and D. S. Nolan, 2012: The effect of vertical shear orientation on tropical cyclogenesis. Quart. J. Roy. Meteor. Soc., 138, 1035-1054, https://doi.org/10.1002/qj.977.

Ray, P., and T. Li, 2013: Relative roles of circumnavigating waves and extratropics on the MJO and its relationship with the mean state. J. Atmos. Sci., 70, 876-893, https://doi.org/10.1175/ JAS-D-12-0153.1.

Riemer, M., and S. C. Jones, 2014: Interaction of a tropical cyclone with a high-amplitude, midlatitude wave pattern: Waviness analysis, trough deformation and track bifurcation. Quart. J. Roy. Meteor. Soc., 140, 1362-1376, https://doi.org/10.1002/ qj.2221.

Rivière, G., 2009: Effect of latitudinal variations in low-level baroclinicity on eddy life cycles and upper-tropospheric wave-breaking processes. J. Atmos. Sci., 66, 1569-1592, https:// doi.org/10.1175/2008JAS2919.1.

_ 2010: Role of Rossby wave breaking in the west Pacific teleconnection. Geophys. Res. Lett., 37, L11802, https://doi.org/ 10.1029/2010GL043309.

_- and I. I. Orlanski, 2007: Characteristics of the Atlantic stormtrack eddy activity and its relation with the North Atlantic Oscillation. J. Atmos. Sci., 64, 241-266, https://doi.org/10.1175/ JAS3850.1.

Saha, S., and Coauthors, 2014: The NCEP Climate Forecast System version 2. J. Climate, 27, 2185-2208, https://doi.org/10.1175/ JCLI-D-12-00823.1.

Samanta, D., M. K. Dash, B. N. Goswami, and P. C. Pandey, 2016: Extratropical anticyclonic Rossby wave breaking and Indian summer monsoon failure. Climate Dyn., 46, 1547-156, https:// doi.org/10.1007/s00382-015-2661-7.

Slade, S. A., and E. D. Maloney, 2013: An intraseasonal prediction model of Atlantic and east Pacific tropical cyclone genesis. Mon. Wea. Rev., 141, 1925-1942, https://doi.org/10.1175/ MWR-D-12-00268.1.

Strong, C., and G. Magnusdottir, 2008: How Rossby wave breaking over the Pacific forces the North Atlantic Oscillation. Geophys. Res. Lett., 35, L10706, https://doi.org/10.1029/2008GL033578.

- , and - 2009: The role of tropospheric Rossby wave breaking in the Pacific decadal oscillation. J. Climate, 22, 1819-1833, https://doi.org/10.1175/2008JCLI2593.1.

Thorncroft, C. D., B. J. Hoskins, and M. E. McIntyre, 1993: Two paradigms of baroclinic-wave life-cycle behavior. Quart. J. Roy. Meteor. Soc., 119, 17-55, https://doi.org/ 10.1002/qj.49711950903.

Ventrice, M. J., M. C. Wheeler, H. H. Hendon, C. J. Schreck, C. D. Thorncroft, and G. N. Kiladis, 2013: A modified multivariate Madden-Julian oscillation index using velocity potential. Mon. Wea. Rev., 141, 4197-4210, https://doi.org/10.1175/ MWR-D-12-00327.1.

Vitart, F., A. Leroy, and M. C. Wheeler, 2010: A comparison of dynamical and statistical predictions of weekly tropical cyclone activity in the Southern Hemisphere. Mon. Wea. Rev., 138, 3671-3682, https://doi.org/10.1175/2010MWR3343.1.
- A. W. Robertson, and D. L. Anderson, 2012: Subseasonal to Seasonal Prediction Project: Bridging the gap between weather and climate. WMO Bull., 61 (2), 23-28.

— , and Coauthors, 2017: The Subseasonal to Seasonal (S2S) Prediction Project database. Bull. Amer. Meteor. Soc., 98, 163173, https://doi.org/10.1175/BAMS-D-16-0017.1.

Walsh, K., M. Fiorino, C. Landsea, and K. McInnes, 2007: Objectively determined resolution-dependent threshold criteria for the detection of tropical cyclones in climate models and reanalyses. J. Climate, 20, 2307-2314, https://doi.org/10.1175/JCLI4074.1.

Wang, Z., W. Li, M. S. Peng, X. Jiang, R. McTaggart-Cowan, and C. A. Davis, 2018: Predictive skill and predictability of North Atlantic tropical cyclogenesis in different synoptic flow regimes. J. Atmos. Sci., 75, 361-378, https://doi.org/10.1175/ JAS-D-17-0094.1.

Waugh, D. W., and B. M. Funatsu, 2003: Intrusions into the tropical upper troposphere: Three-dimensional structure and accompanying ozone and OLR distributions. J. Atmos. Sci., 60, 637-653, https://doi.org/10.1175/1520-0469(2003)060<0637: IITTUT $>2.0 . \mathrm{CO} ; 2$.

Wheeler, M., and H. Hendon, 2004: An all-season real-time multivariate MJO index: Development of an index for monitoring and prediction. Mon. Wea. Rev., 132, 1917-1932, https://doi.org/ 10.1175/1520-0493(2004)132<1917:AARMMI > 2.0.CO;2.

Whitaker, J. S., and A. F. Loughe, 1998: The relationship between ensemble spread and ensemble mean skill. Mon. Wea. Rev., 126, 3292-3302, https://doi.org/10.1175/1520-0493(1998)126<3292: TRBESA $>2.0 . \mathrm{CO} ; 2$.

Woollings, T., B. Hoskins, M. Blackburn, and P. Berrisford, 2008: A new Rossby wave-breaking interpretation of the North Atlantic Oscillation. J. Atmos. Sci., 65, 609-626, https://doi.org/ 10.1175/2007JAS2347.1.

Wu, M. C., S. D. Schubert, M. J. Suarez, P. J. Pegion, and D. E. Waliser, 2006: Seasonality and meridional propagation of the MJO. J. Climate, 19, 1901-1921, https://doi.org/10.1175/JCLI3680.1.

Zhang, C., and M. Dong, 2004: Seasonality in the Madden-Julian Oscillation. J. Climate, 17, 3169-3180, https://doi.org/10.1175/ 1520-0442(2004)017<3169:SITMO >2.0.CO;2.

Zhang, F., and D. Tao, 2013: Effects of vertical wind shear on the predictability of tropical cyclones. J. Atmos. Sci., 70, 975-983, https://doi.org/10.1175/JAS-D-12-0133.1.

Zhang, G., and Z. Wang, 2018: North Atlantic extratropical Rossby wave breaking during the warm season: Wave life cycle and role of diabatic heating. Mon. Wea. Rev., 146, 695-712, https:// doi.org/10.1175/MWR-D-17-0204.1.

, T. J. Dunkerton, M. S. Peng, and G. Magnusdottir, 2016: Extratropical impacts on Atlantic tropical cyclone activity. J. Atmos. Sci., 73, 1401-1418, https://doi.org/10.1175/ JAS-D-15-0154.1.

, —— M. S. Peng, and G. Magnusdottir, 2017: Characteristics and impacts of extratropical Rossby wave breaking during the Atlantic hurricane season. J. Climate, 30, 2363-2379, https:// doi.org/10.1175/JCLI-D-16-0425.1. 